\title{
Formulation Design and Preclinical Evaluations of Surface Modified Lipid Nanoparticles-Coupled Gel Encapsulating Dihydroartemisinin for Treatment of Localized Inflammation
}

\author{
Chukwuebuka E. Umeyor 1,*iD, Amarachukwu U. Okonkwo ${ }^{1}$, Ozioma D. Ejielo ${ }^{1}$, \\ Immaculeta C. Umeyor ${ }^{2}$, Emmanuel M. Uronnachi 1 (iD, Calistus D. Nwakile ${ }^{1}$ (D), Ifeanyi J. Okeke ${ }^{1}$, \\ Anthony A. Attama ${ }^{3}$ (D) \\ 1 Nanomedicine and Drug Delivery Research Group, Department of Pharmaceutics and Pharmaceutical Technology, Faculty \\ of Pharmaceutical Sciences, Nnamdi Azikiwe University, Awka 422001, Anambra State, Nigeria \\ 2 Department of Pharmacognosy and Traditional Medicine, Faculty of Pharmaceutical Sciences, Nnamdi Azikiwe \\ University, Awka 422001, Anambra State, Nigeria \\ 3 Drug Delivery and Nanomedicine Research Group, Department of Pharmaceutics, Faculty of Pharmaceutical Sciences, \\ University of Nigeria, Nsukka 410001, Enugu State, Nigeria \\ * Correspondence: ec.umeyor@unizik.edu.ng (C.U.);
}

Scopus Author ID 55647503200

Received: 26.06.2021; Revised: 20.08.2021; Accepted: 24.08.2021; Published: 11.09.2021

\begin{abstract}
Previously, it has been claimed that artemisinin derivatives, e.g., dihydroartemisinin, possess very potent anti-inflammatory activity. The study aimed to formulate gels based on surface-modified nanostructured lipid carrier (NLC) and contain dihydroartemisinin (DHA) to treat localized inflammation. NLC was developed using Softisan ${ }^{\circledR} 154$ and Tetracarpidium conophorum oil and structured using PEG 4000. Physicochemical characterization of NLC, including surface charge, particle size, and encapsulation efficiency (EE\%), was evaluated. NLCwas dispersed in hydroxypropyl cellulose, and the resulting nanogels were evaluated for drug content, ex vivo permeation, and antiinflammatory activity. The surface charge and particle size of NLC ranged from $-15.3 \pm 1.1$ to $-25.5 \pm$ $2.1 \mathrm{mV}$ and $85.5 \pm 8.6-108.7 \pm 5.5 \mathrm{~nm}$ respectively. EE\% of NLC was in the range of $90.0 \pm 1.21-$ $99.3 \pm 1.60 \%$. NLC gels had high drug content $(83-99 \%)$. Ex vivo permeation study showed sustained-release of DHA over $24 \mathrm{~h}$. The gels produced a sustained-release reduction of egg albumininduced inflammation in rats up to $8 \mathrm{~h}$ for 7 days. Development of surface-modified lipid nanoparticlesbased gel containing DHA produced controlled release of the drug localized inflammation.
\end{abstract}

Keywords: anti-inflammation; dihydroartemisinin; gel; nanostructured lipid carrier; Tetracarpidium conophorum oil; transdermal drug delivery.

(C) 2021 by the authors. This article is an open-access article distributed under the terms and conditions of the Creative Commons Attribution (CC BY) license (https://creativecommons.org/licenses/by/4.0/).

\section{Introduction}

Inflammation (generalized or localized) is a complex physicochemical reaction involving enzyme activation, cell migration, tissue breakdown, and mediator release [1]. It is a response of living tissues to physical or chemical assault. It contributes to physiological and pathological processes such as wound healing because tissue survival might be compromised in the absence of inflammation [2]. Non-steroidal anti-inflammatory drugs (NSAIDs) are the mainstay treatment for most inflammatory diseases. NSAIDs, e.g., diclofenac (DIC), ibuprofen 
(IBU), and acetylsalicylic acid (ASA), are the most consumed globally [3]. Unfortunately, the clinical application of NSAIDs is undermined by limitations that threaten their ability to achieve the best efficacy and safety outcomes. Precisely, NSAIDs produce very costly and severe adverse events, including renal, cardiovascular, and gastrointestinal complications, with serious economic and health impacts [4]. In the light of these challenges, it has become important to seek alternative drugs which are safer and with minimal adverse effects for the treatment of inflammation. Recently, artemisinin and its derivatives, including dihydroartemisinin (DHA), have been reported to possess potent anti-inflammatory activity [5-9]. The anti-inflammatory activity of DHA is not widely elucidated in literature, but in a study, it was shown that DHA molecules attenuate nitric oxide synthase protein resulting in inhibition of the mobilization and release of interleukin-6, tumor necrosis factor- $\alpha$, and inflammatory mediator nitric oxide from macrophages [8]. In another study, DHA effectively inhibited Th-cells differentiation in vitro and reduced the onset of autoimmune encephalomyelitis (EAE) and its clinical symptoms by modulating the mammalian or mechanistic target of the rapamycin (mTOR) pathway [10]. However, DHA is limited by poor aqueous solubility $\left(<2 \mathrm{mg} / \mathrm{ml}\right.$ at $30{ }^{\circ} \mathrm{C}$ ) and low bioavailability (about $12 \%$ ), and short halflife (34 - $90 \mathrm{~min}$ ) [11-13], and these factors pose great challenges in the design of its dosage forms. Since available literature has no report or claim of a nanotechnology-based formulation containing DHA for the treatment of inflammation and coupled with its excellent safety and efficacy profiles as an antimalarial agent, there is a need to develop a carrier system for DHA that will improve its solubility and bioavailability as well as enhance its efficacy and safety as an anti-inflammatory agent because DHA is lipophilic $(\log \mathrm{P}=<3)$ with molecular weight $<500$ Da which endows it with a good potential for skin penetration. Furthermore, repositioning DHA for the treatment of inflammatory conditions is important because it will increase the clinical use of DHA and encourage further research in drug repurposing for enhanced drug use [14].

Consequently, the most promising technique to improve the solubility, bioavailability, dermal penetration, skin retention, and efficacy of DHA for resolution of skin inflammation is the use of second-generation solid lipid nanoparticles called nanostructured lipid carriers (NLC), which have numerous advantages compared to SLN and other nanoparticulate colloidal drug delivery systems. The encapsulation of DHA in NLC would lead to high drug entrapment, alteration of drug release profile with enhanced solubility and bioavailability, improved stability, localized delivery and retention at the target site, reduced or no side effects, administration of low dose and reduced dosing frequency, and improved patient compliance $[15,16]$. Furthermore, the profound lipid composition and small particle size of NLC will facilitate increased penetration of a high amount of DHA into the skin through the stratum corneum lipid bilayer. The nanoparticles can adhere tightly to the skin surface and produce controlled drug release. NLC improves skin hydration after topical application and produces an occlusive effect that promotes increased penetration of drugs across the dermal layers [1719]. Recently, several studies have reported using NLC as a viable carrier system for enhanced transdermal delivery of some drugs following topical application [20-26]. More so, our research group has reported the use of colloidal lipid dispersions that were surface modified with polyethylene glycol (PEG 4000) or PEGylation for improved skin targeting and localized delivery of drugs [27, 28]. Other researchers have reported similar findings [29, 30]. PEGylated lipid carrier systems are tailor-made drug delivery systems that have been shown to improve the aqueous solubility and penetration capacity of drugs, provide high local dermal levels with 
prolonged activity due to very close contact with dermal layers, and reduced exposure of tissues to drug effects [28]. It was hypothesized that the successful design and entrapment of DHA in PEGylated NLCwould favor enhanced solubility and bioavailability with improved trafficking of the drug through the dermal layers and production of localized anti-inflammatory effect.

Therefore, the study aimed to develop DHA-loaded NLC using biomaterials including Tetracarpidium conophorum oil and Softisan ${ }^{\circledR} 154$. The optimized DHA-NLC formulations were matrixed in hydroxypropyl cellulose (HPC) to obtain a semisolid dosage form, and its preclinical characteristics were evaluated for topical anti-inflammatory activity.

\section{Materials and Methods}

\subsection{Materials.}

Dihydroartemisinin was donated by Greenlife Pharmaceuticals Ltd, Lagos, Nigeria. Mirapain ${ }^{\circledR}$ gel was bought from Miraflash Nigeria Limited, Ogun State, Nigeria. Softisan ${ }^{\circledR} 154$ was donated by Fa.Condea Chemie GmbH, Germany. Kolliphor ${ }^{\circledR} \mathrm{P} 188$ was provided by BASF SE, Ludwigshafen, Germany. Polyethylene glycol 4000 (PEG 4000) was a gift from Carl Roth GmbH and Co. KG, Karlsruhe, Germany. Hydroxypropyl cellulose (HPC) powder was kindly donated by Nippon Soda Chemical Company Ltd., Tokyo, Japan. Fused calcium chloride was purchased from Xilong Scientific Co. Ltd Guangdong, China. Tetracarpidiumconophorum oil used in the study was locally processed in our laboratory.

\subsection{Methods.}

\subsubsection{Formulation of PEGylated lipid matrix.}

Lipid matrix based on T. conophorum oil and a hydrogenated lipid from palm oil, Softisan ${ }^{\circledR} 154$ (S154) at oil:S154 ratio of 1:2 was prepared by fusion [28]. Appropriate quantities of the lipids were weighed, melted together in a thermostatically controlled water bath (Huanghua Instruments Co. Ltd., China) at $90{ }^{\circ} \mathrm{C}$ with stirring until a homogenous melt of the admixtures was obtained. Thereafter, the lipid melt was treated with poly(ethylene glycol) (PEG 4000, $10 \% \mathrm{w} / \mathrm{w}$ ) with adequate stirring using a magnetic stirrer at 1,000 rpm for $3 \mathrm{~h}$ (for 2 cycles) to yield a PEGylated lipid matrix, which was then stirred at room temperature $\left(27 \pm 2{ }^{\circ} \mathrm{C}\right)$ until solidification. The lipid matrix was stored in a screw-cap and airtight plastic container until needed.

\subsubsection{Fabrication of nanostructured lipid carriers of dihydroartemisinin.}

Batches of NLC loaded with DHA were prepared by hot homogenization technique using a high-pressure homogenizer [24] with slight modification. PEGylated and nonPEGylated lipid matrices were melted at $90{ }^{\circ} \mathrm{C}$ and loaded with increasing concentrations of DHA $(0.1,0.2,0.3 \% \mathrm{w} / \mathrm{w})$, respectively. Polysorbate 80 (Tween $\left.{ }^{\circledR} 80,5 \% \mathrm{w} / \mathrm{w}\right)$ was added to the lipid phase to enhance the solubilization of DHA. Then, Kolliphor ${ }^{\circledR} \mathrm{P} 188(2 \% \mathrm{w} / \mathrm{w})$ was solubilized in distilled water to prepare the aqueous phase, which was brought to the same temperature as the lipid phase and added carefully to the drug-loaded molten lipid. The preemulsion was immediately subjected to sonication for $5 \mathrm{~min}$ followed by high shear mixing (JB-90S, Daica Scientific Co., Ltd, China) at 8,000 rpm for 15 min with cooling in ice and thawing at room temperature to produce an oil-in-water nanoemulsion. The nanoemulsion was 
transferred into wide-mouthed plastic containers and dried in a desiccator containing fused calcium chloride as the desiccant to obtain solid nanoparticles. NLC containing no drug was also formulated using a PEGylated lipid matrix to serve as a negative control. The compositions of the NLC are shown in Table 1.

\subsubsection{Evaluation of surface morphology.}

The morphological characteristics of the DHA-loaded NLCs were determined using a PhenomProx scanning electron microscope (SEM) (PhenomWorld, Eindhoven, Netherlands). The samples were placed on the sample holder of the SEM at $50{ }^{\circ} \mathrm{C}$ to freeze-fracture the sample. After 5 min of instrument stabilization, surface imaging of the NLCs was carried out at $15 \mathrm{kV}$, and images were focused using a digital NavCam mode and transferred to Phenom suite software for image analysis.

Table 1.Composition of nanostructured lipid carriers of dihydroartemisinin (\%w/w).

\begin{tabular}{c|c|c|c|c|c|c} 
Batch & LM & DHA & T80 & SA & KP188 & Distilled water, q. $\mathbf{s}$ \\
\hline F1 & 10.0 & 0.1 & 5.0 & 5.0 & 2.0 & 100.0 \\
\hline F2 & 10.0 & 0.2 & 5.0 & 5.0 & 2.0 & 100.0 \\
\hline F3 & 10.0 & 0.3 & 5.0 & 5.0 & 2.0 & 100.0 \\
\hline F4 & 10.0 & - & 5.0 & 5.0 & 2.0 & 100.0
\end{tabular}

Batches F1, F2, and F4 were prepared using PEGylated lipid matrix, while F3 was formulated using a nonPEGylated lipid matrix. F1, F2, and F3 are dihydroartemisinin-loaded NLC, while F4 is unloaded NLC. Key: LM - lipid matrix; DHA - dihydroartemisinin; T80 - Tween $^{\circledR}$ 80; SA - sorbic acid; KP188 - Kolliphor ${ }^{\circledR}$ P188. [-] indicates the absence of drugs.

\subsubsection{Determination of particle size, polydispersity index, and surface charge.}

The mean particle diameter and polydispersity index (PDI) of the nanoparticles were determined by photon correlation spectroscopy (PCS) using a Zetasizer Nano ZS (Malvern Instruments Ltd, Worcestershire, UK) equipped with a $10 \mathrm{mw}$ He-NE laser at the wavelength of $633 \mathrm{~nm}$ with the run time of $60 \mathrm{~s}$ and a backscattering angle of $173^{\circ}$ at $25 \pm 2^{\circ} \mathrm{C}$. All samples were diluted with distilled water to obtain a suitable scattering intensity before photon correlation spectroscopy analysis was done. The nanoparticles' surface charge (zeta potential, ZP) was determined by electrophoretic mobility measurements using a Zetasizer Nano ZS. The measured electrophoretic mobility data obtained following dilution of samples in phosphate buffer solution (PBS, pH 7.4) were converted into zeta potential using HelmholtzSmoluchowski equation. The processing and calculation were done using machine-based software within the system. All measurements were done in triplicate.

\subsubsection{Evaluation of entrapment efficiency and loading capacity.}

The drug content of the drug-loaded NLC was determined using the method reported with slight modifications [31]. Different standard concentrations of DHA were prepared using a concentration range of $10-100 \mathrm{mg} \%$ for Beer-Lambert's plot. To achieve this, an amount of the drug was gently mixed with $10 \mathrm{ml}$ ethanol and allowed to equilibrate for $15 \mathrm{~min}$ at ambient temperature. After $15 \mathrm{~min}$, the mixture was filtered using a millipore membrane filter $(0.45$ $\mu \mathrm{m}$, Mumbai, India), and the filtrate (stock solution) was diluted to $500 \mu \mathrm{g} / \mathrm{ml}$ using ethanol. Then, aliquots of this solution were measured into two different glass test tubes and further mixed with $1 \mathrm{M} \mathrm{HCl}$. The test tubes were incubated at $90^{\circ} \mathrm{C}$ in the thermostatically controlled water bath for $15 \mathrm{~min}$. The reaction was quenched with $3 \mathrm{ml}$ of ethanol and absorbance taken spectrophotometrically (Cary 60 UV-Vis Spectrophotometer, Agilent Technologies, Malaysia) 
connected to a ProDisplay P202 bundle PC. The sample was poured into quartz cells $(10 \mathrm{~mm}$, $3500 \mu \mathrm{l}$; Agilent Technologies Life Sciences and Chemical Analysis, Waldbronn, Germany), and analysis was done at a pre-determined wavelength of $371 \mathrm{~nm}$ using ethanol as blank. After that, $0.1 \mathrm{~g}$ of the DHA-loaded NLC equivalent to $10 \mathrm{mg}$ of DHA was soaked in $100 \mathrm{ml}$ of double-distilled water, shaken vigorously, and then left undisturbed for $48 \mathrm{~h}$ in a $100 \mathrm{ml}$ volumetric flask. After $48 \mathrm{~h}$, the samples were centrifuged for $15 \mathrm{~min}$ at 4,000 rpm, and the supernatant containing the free (unentrapped) drug in each formulation was filtered using a disposable membrane filter $(0.45 \mu \mathrm{m})$, adequately diluted with ethanol and treated as described above for estimation of drug content spectrophotometrically. The mean of triplicate determinations was taken as the absorbance. The actual drug content of the NLC was calculated considering the initial amount of drug-loaded in the formulations. Furthermore, the entrapment efficiency (EE \%) was calculated to compare the quantities of DHA theoretically loaded in the NLC with the actual quantities obtained from the entrapment study using the following equation:

\section{Total amount of drug - Amount of drug in the sup erna $\tan t$ \\ $\mathrm{EE} \%=\quad$ Total amount of drug $\quad$ X100 ... Equation 1}

The loading capacity expresses the ratio between the entrapped active pharmaceutical ingredient (API) and the total weight of the lipid. It was determined using the equation:

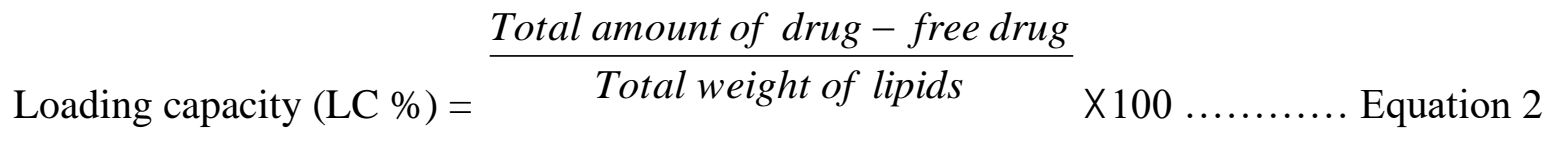

2.2.6. Differential scanning calorimetry.

Thermal properties of the lipid matrix, DHA, Softisan ${ }^{\circledR} 154, T$. conophorum oil, and a representative DHA-loaded NLC were determined using a differential scanning calorimeter (DSC) (Mettler-Toledo, Beaumont Leys, Leicester, UK) equipped with the rugged multiSTARe sensor with 56 thermocouples and STARe Software option 13.0. About $10 \mathrm{mg}$ of each formulation was separately weighed into an aluminum-plated crucible, hermetically sealed, and the thermal behavior determined in the range of $70-280{ }^{\circ} \mathrm{C}$ at a heating rate of 5 ${ }^{\circ} \mathrm{C} / \mathrm{min}$. The temperature was held at $80{ }^{\circ} \mathrm{C}$ for $10 \mathrm{~min}$ and, after that, cooled at the rate of $5-$ $10{ }^{\circ} \mathrm{C} / \mathrm{min}$. Baselines were determined using an empty crucible, and all the thermograms were baseline-corrected.

2.2.7. Fourier transform infrared (FT-IR) spectroscopy for compatibility evaluation.

FT-IR spectroscopic analysis was conducted on dihydroartemisinin (DHA) and selected DHA-loaded and unloaded formulations using FT-IR M530 Spectrophotometer (Buck Scientific, Connecticut, USA), and the spectrum was recorded in the wavelength region of 3500 to $1000 \mathrm{~cm}^{-1}$ with a threshold of 1.303 , the sensitivity of 50 and resolution of $2 \mathrm{~cm}^{-1}$ range. A smart attenuated total reflection (SATR) accessory was used for data collection. The potassium bromated $(\mathrm{KBr})$ plate used for the study was cleaned with a tri-solvent (acetone- toluenemethanol at 3:1:1 ratio) mixture for baseline scanning. A $0.1 \mathrm{~g}$ of each sample was mixed with $0.1 \mathrm{ml}$ nujul diluent. The solution was introduced into the $\mathrm{KBr}$ plate and compressed into discs by applying a pressure of 5 tons for $5 \mathrm{~min}$ in a hydraulic press. The pellet was placed in the 
light path, and the spectrum was obtained. Spectra were collected in 60 s using Gram A1 spectroscopy software, and the chemometrics was performed using TQ Analyzer1.

\subsubsection{X-ray diffractometry.}

Wide-angle X-ray diffraction (WAXD) analysis was performed using an x-ray diffractometer (Empyrean ${ }^{\circledR}$ Nano Edition diffractometer, Malvern Panalytical Ltd, Royston, UK) to study the crystalline structures of DHA, Softisan ${ }^{\circledR} 154$, lipid matrix, and selected drugloaded formulation, which was placed in flat sample holders respectively. The diffractometer is equipped with a camera length of $480 \mathrm{~mm}$, a sealed high-resolution X-ray tube, temperaturecontrolled capillary holder, low-noise, and hybrid pixel area detectors. The diffraction patterns were measured using a Cu-based anode material $(40 \mathrm{~mA}$ and $45 \mathrm{kV})$, and obtained data were analyzed using NGRL ${ }^{\circledR}$ Flat Programme software and filtered using Ni filter with $2 \theta$ angle of $10-70^{\circ}$.

\subsubsection{Preparation of DHA-loaded NLC gels.}

Hydroxypropyl cellulose (HPC) was used as the base for the nanostructured lipid particles containing DHA to render it rheologically acceptable for dermal application. Briefly, (HPC, $10 \% \mathrm{w} / \mathrm{w}$ ) was dispersed in water and allowed to hydrate overnight (24 h), after which glycerol and propylene glycol were added. The dispersion was neutralized using triethanolamine with gentle stirring until a suitable semisolid formulation (plain transparent gel) was obtained. For the preparation of the gels, HPC was added to a dispersion of NLC (5 $\% \mathrm{w} / \mathrm{w}$ ) with stirring, followed by the addition of triethanolamine. All products were kept at ambient temperature for $24 \mathrm{~h}$ to ensure no entrapped air bubbles before they were dispensed in transparent plastic containers, securely closed, and stored at room temperature until used.

\subsubsection{Measurement of $\mathrm{pH}$.}

As the formulations are for topical application, $\mathrm{pH}$ measurement is essential to guarantee the non-irritating nature of the nanogels. A digital $\mathrm{pH}$ meter (Labtech, India) previously calibrated using buffer solutions with $\mathrm{pH} 4$ and 8 , was used with temperature compensation at $25 \pm 2{ }^{\circ} \mathrm{C}$, to determine the $\mathrm{pH}$ of the nanogels by direct immersion of the $\mathrm{pH}$ meter electrode into samples immediately after formulation, and after 30, and 90 days of storage in triplicate, and the average $\mathrm{pH}$ and standard deviation of each batch calculated.

\subsubsection{Spreadability determination.}

About $1 \mathrm{~g}$ quantity of the gel formulation was placed within a circle of $1.0 \mathrm{~cm}$ diameter pre-marked on one side of a glass slide, and another glass slide was placed over it. A weight of $200 \mathrm{~g}$ was placed to rest on the upper glass slide for $5 \mathrm{~min}$. The diameter occupied by the spreading gel was noted, and spreadability was calculated in triplicate as follows:

$$
\text { Spreadability }(\%)=\frac{\text { Increase in diameter }}{\text { Initial diameter }} \times 100 \ldots \ldots \ldots \ldots \ldots \ldots \ldots \ldots \text { Equation } 3
$$




\subsubsection{Determination of in vitro occlusivity.}

Distilled water $(100 \mathrm{ml})$ was poured into a glass beaker $(250 \mathrm{ml})$ and covered with a filter paper (Whatman No. 1), which was tied in place with a rubber band. Then, $0.2 \mathrm{~g}$ of each batch of the gel was distributed evenly on the filter paper covering the glass beaker, and the setup was weighed. A similar beaker was filled with distilled water covered with filter paper and weighed without applying the gel to serve as a control. Both glass beakers (gel-bearing and non-bearing) were stored at $37 \pm 0.5{ }^{\circ} \mathrm{C}$ for $48 \mathrm{~h}$, after which the weight differences due to evaporation of water through the filter paper were obtained and used to calculate the occlusivity factor ' $F$ ' at 24, and 48 as follows:

$$
\text { Occlusivity factor, } \mathrm{F}=100\left[\frac{A-B}{A}\right] \ldots \ldots \ldots \ldots \ldots \ldots \ldots \ldots \ldots \ldots \ldots \text { Equation } 4
$$

Where A $(\%)$ and $\mathrm{B}(\%)$ are the water fluxes (\% water loss) through the non-bearing and gelbearing filters, respectively.

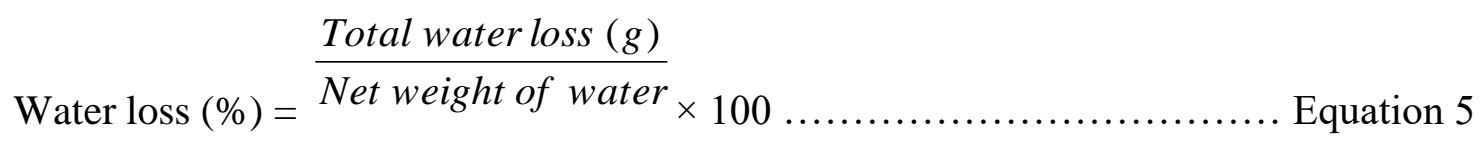

\subsubsection{Evaluation of drug content.}

A $1 \mathrm{~g}$ of each NLC-based DHA gel preparation was weighed and placed in a $100 \mathrm{ml}$ volumetric flask. Then, $50 \mathrm{ml}$ of ethanol was added, mixed thoroughly, and sonicated continuously for $30 \mathrm{~min}$. The volume was made up to mark with the solvent and then centrifuged at 4,000 rpm for $15 \mathrm{~min}$. This was filtered using a membrane filter $(0.45 \mu \mathrm{m}$, Mumbai, India). The drug content of the filtrate was spectrophotometrically scanned at $371 \mathrm{~nm}$ as earlier described, and drug content efficiency was calculated using the formula:

$$
\text { Drug content efficiency }(\%)=\frac{\text { Actual drug content }}{\text { Theoretical drug content }} \times 100 \ldots \ldots \ldots \ldots \ldots \text { Equation } 6
$$

\subsubsection{Nanogel viscometry.}

The viscosity of each gel formulation was measured using a digital rotating viscometer (NDJ5S, Searchtech Instrument, China) with spindle number 04 at different speeds $(6,12,30$, and $60 \mathrm{rpm}$ ). The viscosity was measured with a dispersion of the gels in a solvent to simulate the use condition. The spindle was immersed in the sample in a $50 \mathrm{ml}$ beaker and attached to the coupling nut such that the gel level was at the groove on the shaft. The test was run at ambient laboratory temperature $\left(27 \pm 1{ }^{\circ} \mathrm{C}\right)$, and the viscosity $(\mathrm{mPaS})$ and percent torque at each rotation speed were recorded in triplicate.

\subsubsection{In vitro drug release study of drug-loaded nanogel.}

The membranes technique [32] was adopted with slight modifications in evaluating in vitro release of DHA from the gel. The membraneless method was used to allow the release medium to be in direct contact with the surface of the gel, thereby simulating the use condition. The gel ( $1 \mathrm{~g})$ was transferred into a graduated test tube and was placed in a thermostatically controlled water bath (Huanghua Instruments Co. Ltd., China) and maintained for 10 min. 
Phosphate buffered saline, PBS $(\mathrm{pH}=5.5,2.0 \mathrm{ml})$, which served as release medium and preequilibrated at $37 \pm 0.5^{\circ} \mathrm{C}$, was layered over the surface of the gel. After removing the medium at a pre-determined one-hour interval for $24 \mathrm{~h}$, the test tube was cleared, weighted, and layered with fresh PBS to maintain sink condition. The procedure was repeated until less than $10 \%$ of the gel was retained in each case, and withdrawn samples were analyzed using UV/Vis spectrophotometer as earlier described. The test was repeated using DHA-loaded NLC (F3) for the accuracy of the comparison. The amount of DHA in the samples was determined in triplicate according to the formula:

\section{Cumulative amount of DHA released \\ Cumulative DHA released rate $=$ Initial amount of DHA $\quad \times 100 \%$ Equation 7}

The data obtained from the in vitro release study were used for kinetic modeling. Model fitting into zero-order, first-order, Higuchi, and Korsmeyer Peppas was done to study the mechanism behind the release pattern of the gels.

\subsection{Animal care and use protocols.}

Randomly selected white albino rats (BALB/c strain; males and females) weighing 200 - $240 \mathrm{~g}$ were procured from the animal breeding center, Department of Pharmacology and Toxicology, Faculty of Pharmaceutical Sciences, Nnamdi Azikiwe University, Awka, Nigeria. Animals were treated according to the National Institute of Health (NIH Publications no. 8023, as revised in 1978) guidelines for animal care. They were housed in a regulated environment $\left(25 \pm 2^{\circ} \mathrm{C}, 12 \mathrm{~h}\right.$ light/dark cycle, light cycle starting at $\left.7 \mathrm{am}\right)$, acclimatized for 1 week before the study, fed standard rodent pellets (Guinea feeds Ltd, Nigeria), and allowed free access to clean, fresh water in glass water bottles ad libitum. Cage-side clinical observations of the rats were made throughout the study period. All animal experiments complied with the ARRIVE guidelines and were performed in accordance with the U.K. Animals (Scientific Procedures) Act, 1986 and associated guidelines, EU Directive 2010/63/ EU for animal experiments. All animal use protocols were approved by the Animal Care and Use Committee of the Faculty of Pharmaceutical Sciences.

\subsubsection{Ex vivo permeation study using murine skin.}

The ex-vivo skin permeation studies were carried out using rat abdominal skin $[33,34]$ procured from Wistar rats which were sacrificed through prolonged anesthesia. The hairs of the skin were carefully shaved using a surgical blade, and the full skin was removed, exposing the dermis, which was properly rinsed with normal saline to remove residual fat. The skin (thickness 1.5 - $2.5 \mathrm{~mm}$ ) was fixed on a Franz diffusion cell (PermeGear Inc., Hellertown, PA, USA), having a permeation area of $3.14 \mathrm{~cm}^{2}$. To maintain sink condition, the receptor compartment was filled with $15 \mathrm{ml} \mathrm{PBS} \mathrm{(pH} \mathrm{7.4)} \mathrm{stirred} \mathrm{continuously} \mathrm{at} 500 \mathrm{rpm}$ at $32 \pm 0.5^{\circ} \mathrm{C}$, which is equivalent to human skin surface temperature. Weighed amount ( $\sim 0.1 \mathrm{~g}$ equivalent to $10 \mathrm{mg}$ of DHA) of DHA-loaded nanogels were applied carefully to the skin in the donor compartment and evenly spread using the flat surface of a spatula to maintain intimacy with the skin. At pre-determined time intervals up to $24 \mathrm{~h}, 0.5 \mathrm{ml}$ of sample was withdrawn from the receptor compartment and replaced with an equal volume of the fresh diffusion medium. All samples were filtered through a $0.45 \mu \mathrm{m}$ membrane filter, diluted appropriately, analyzed spectrophotometrically as earlier described against the blank (PBS), and the cumulative amount 
of DHA permeated per unit area of rat skin was calculated and plotted against time. The test was repeated using DHA-loaded NLC (F3) as a positive control in triplicate.

\subsubsection{Skin tolerance test.}

The evaluation of the skin tolerance potential of DHA nanogel was carried out according to the method previously described [35] with slight modifications. In this study, four rats $(180-200 \mathrm{~g})$ were used, and $24 \mathrm{~h}$ before the experiment, rat dorsal skin was shaved free of hairs. DHA nanogels $(1 \mathrm{~g})$ was applied to the dorsal side of the animal $(1-2)$ respectively and uniformly spread within an area of $0.4 \mathrm{~cm}^{2}$ and covered with adhesive tape. The dorsal skin of the third rat was treated with $1 \%$ formaldehyde solution as a positive control, while the fourth animal was treated with placebo gel (plain gel) which served as a negative control. The gel was applied once daily for 3 days, and the skin was observed for any visible change such as redness, oedema, and skin rash.

\subsubsection{Topical anti-inflammatory activity study.}

Wistar rats $(\mathrm{n}=36)$ were randomly selected and divided into six groups of six animals per group. Group 1 received 0.2 g placebo gel (negative control), group 2 received $0.2 \mathrm{~g}$ DHAloaded NLC (F3) (positive control), and groups $3-5$ received $0.2 \mathrm{~g}$ of batches LNG1 - 3 respectively; while group 6 received $0.2 \mathrm{~g}$ of a commercial anti-inflammatory gel (Mirapain ${ }^{\circledR}$ ). All tested samples and controls were massaged gently over $0.5 \mathrm{~cm}^{2}$ of skin into the subplantar region of the left hind paw of the rats. After $1 \mathrm{~h}, 0.1 \mathrm{ml}$ of fresh undiluted egg albumin was subcutaneously injected into the left hind paw, according to earlier reports [36, 37]. The paw volume was measured before drug administration and then at 1, 2, 3, 4, 5, 6, 7, and $8 \mathrm{~h}$ for 7 days after egg albumin injection using a digital plethysmometer (Basile, Comerio, Italy). The percentage reduction of oedema was calculated as follows:

$$
\text { Oedema reduction }=\frac{\text { oedema }(\text { control })-\text { oedema }(\text { test })}{\text { oedema }(\text { control })} \times 100 \ldots \ldots \ldots \ldots \ldots \text { Equation } 8
$$

\subsection{Storage stability study.}

Storage stability study proceeded according to slightly modified ICH Harmonized Tripartite Guidelines for stability testing of new drug substances and products Q1A (R2) [38]. DHA nanogels were stored under different conditions: $25 \pm 2{ }^{\circ} \mathrm{C} / 60 \pm 5 \% \mathrm{RH}$ and $40 \pm 2{ }^{\circ} \mathrm{C} / 75$ $\pm 5 \% \mathrm{RH}$. The stored products were visually examined for any signs of instability, including discoloration and phase separation. In addition, the formulations were analyzed concerning drug content efficiency after 90 days of storage according to the previously described procedure and compared with data obtained from fresh nanogel formulations.

\subsection{Statistical analysis.}

Data obtained were presented as mean \pm standard deviation. SPSS 8.0 for Windows was applied for the ANOVA-based technique, while a student t-test was used to determine any significant differences between test samples and the control. Differences were considered statistically significant when $\mathrm{p}<0.05$. 


\section{Results and Discussion}

\subsection{Morphological profile of NLC.}

SEM was used to evaluate the morphological principles of the nanoparticles, and the observed microstructures are shown in Figure 1. A representative micrograph of NLC containing DHA revealed particles with smooth surface morphology with a light-colored outer layer which might be attributed to the PEG chains [30]. It also showed that the particles had both spherical and non-spherical (anisometric) structures. This agrees with the light-colored outer layer, which was observed in our previous report [39]. Thus, the representative micrograph of the DHA-loaded NLC had multi-sized microstructures as confirmed by the measured PDI. The smooth morphology of the NLC is a very important attribute that might favor topical application as it might not lead to skin sensitization and irritation.

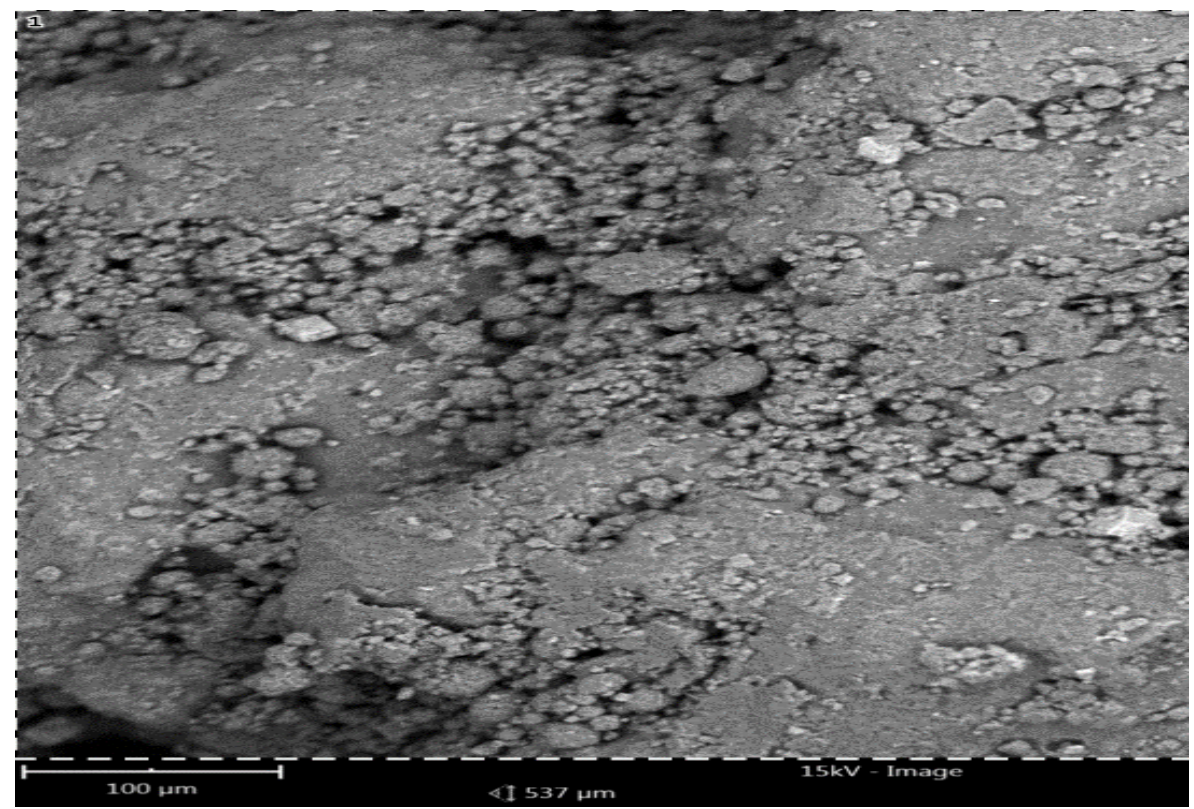

Figure 1. Scanning electron microscope (SEM) image of representative dihydroartemisinin-loaded NLC showing spherical and non-spherical particles.

\subsection{Size, polydispersity index, and zeta potential.}

The particle sizes and polydispersity indices (PDI) of NLC measured by PCS as shown in Table 2 indicate that the nanoparticles had a relatively wide particle size distribution without any significant $(\mathrm{p}<0.05)$ variations in their particle diameter. Generally, the results revealed that drug loading influenced size distribution as particle size increased with increased drug loading [39]. Batch F3 (non-PEGylated) containing 0.3\%w/w DHA gave the largest particle size of $108.7 \pm 1.5 \mathrm{~nm}$, whereas the placebo NLC (PEGylated) recorded a small size of $85.5 \pm$ $8.6 \mathrm{~nm}$. The overall small particles sizes of the NLC might be due to increased surfactant concentration in the formulations as it has been shown that surfactant concentration $>4 \% \mathrm{w} / \mathrm{w}$ yields smaller sizes by reducing the oil-water interfacial tension to a limit below that of the surfactant [14]. PDI is applied in measuring the size distribution of the particles of the NLC in a sample. It has been shown that nanoparticles with uniform particle size distribution have a PDI range from 0.1 to 0.7 , whereas those with broad size distribution have a PDI > 0.7 [24]. The PDI values of the NLC ranged between 0.24 and 0.77 , indicating that most of the batches had uniform particle size distribution. Zeta potential (surface charge) defines the stability of 
colloidal particles as it indicates the degree of repulsion between similarly charged particles. Generally, nanoparticles with high zeta potential profiles experience strong repulsion and enhanced stability in dispersion. The values of zeta potential obtained from the study indicate that the nanoparticles will counter aggregation because they have sufficient charge and charge mobility. Table 2 showed that the measured zeta potential (ZP) values of the nanoparticles ranged from -15 to $-22 \mathrm{mV}$ for PEGylated NLC (F1, F2, and F4), while the non-PEGylated NLC (F3) had a surface charge of $-25 \mathrm{mV}$. This is consistent with an earlier report that surface modification using PEG lowers surface charge due to the ethylene oxide (EO) chain of PEG, which induces shifting of the shear plane of the nanoparticles into the aqueous phase resulting in decreased ZP [30, 40]. However, the recorded zeta potential profile of the nanoparticles will facilitate prolonged physical stability since the NLC were fabricated using surfactants, e.g., Tween ${ }^{\circledR} 80$, which have been reported to stabilize colloidal dispersions by electrostatic and steric stabilizations [41]. The larger particle sizes and the negative zeta potential values confirm the successful coating of the surfaces of the NLC using PEG 4000 due to its shielding effect at the surface of the nanoparticles.

Table 2. Some physicochemical properties of the NLC.

\begin{tabular}{l|c|c|c|c|c}
\multirow{2}{*}{ Batch } & $\begin{array}{c}\text { Particle size } \\
(\mathbf{n m})\end{array}$ & Polydispersity index & $\begin{array}{c}\text { Zeta potential } \\
(\mathbf{m V})\end{array}$ & EE $(\boldsymbol{\%})$ & LC $(\boldsymbol{\%})$ \\
\hline F1 & $71.1 \pm 7.2$ & $0.43 \pm 0.12$ & $-20.1 \pm 0.2$ & $90.0 \pm 1.21$ & $10.38 \pm 3.1$ \\
\hline F2 & $87.8 \pm 2.7$ & $0.64 \pm 0.02$ & $-15.3 \pm 1.1$ & $98.0 \pm 0.95$ & $11.85 \pm 2.2$ \\
\hline F3 & $108.7 \pm 1.5$ & $0.77 \pm 0.11$ & $-25.5 \pm 2.1$ & $99.3 \pm 1.60$ & $22.72 \pm 1.5$ \\
\hline F4 & $85.5 \pm 8.6$ & $0.24 \pm 0.05$ & $-22.2 \pm 1.0$ & - & -
\end{tabular}

Batches F1, F2, and F4 were prepared using PEGylated lipid matrix, while F3 was formulated using nonPEGylated lipid matrix. F1, F2, and F3 are dihydroartemisinin-loaded NLC, while F4 is unloaded NLC. EE entrapment efficiency; LC - loading capacity. Data were presented as mean \pm standard deviation $(\mathrm{SD})$ at $\mathrm{n}=3$.

\subsection{Entrapment efficiency and loading capacity.}

The result of the study shown in Table 2 revealed that NLC had excellent EE\% ranging from $90.0 \pm 1.21-99.3 \pm 1.60 \%$, and $\mathrm{LC} \%$ ranging from $10.98 \pm 3.1-22.72 \pm 1.5$. The recorded data showed that increased drug loading resulted in increased EE\%. Precisely, NLC loaded with $0.3 \%$ w/w DHA gave the highest EE\% of $99.3 \pm 1.60 \%$ while NLC loaded with $0.1 \% \mathrm{w} / \mathrm{w}$ DHA recorded the least EE\% of $90.0 \pm 1.21$. This observation was in agreement with the trend of $\mathrm{LC} \%$ data. The increased $\mathrm{EE} \%$ and $\mathrm{LC} \%$ attained by the DHA-loaded formulations might be due to the high entrapment of DHA molecules within the various distortions produced in the matrix followed by their solubilization surfactants. This observation was in agreement with earlier reports $[42,43]$. These excellent results also highlight the strong affinity of the lipophilic DHA molecules with T.conophorum oil and Softisan ${ }^{\circledR} 154$ molecules as well as due to the high solubility of DHA within the lipid matrix ${ }^{41}$. These values are considerably higher than the EE\% measured in the DHA-loaded LNE in our previous study [39], which could be attributed to the highly disordered PEGylated solid lipid core with numerous imperfections which encapsulated more drug molecules solubilized in the oily core. Furthermore, surface decoration of the lipid matrix using PEG 4000 might have contributed to the high drug entrapment of the DHA-loaded NLC since it has been reported that PEGylated lipids favor increased drug encapsulation due to the formation of mixed micelles [28, 30]. Moreover, the high LC\% proves that DHA was adequately entrapped into the lipid matrix following its interaction with the molecules of the lipid matrix and the surface modifier. 


\subsection{Thermal analysis.}

Thermal analyses of DHA, Softisan ${ }^{\circledR} 154, T$. conophorum oil, lipid matrix, and a selected optimized formulation were determined using DSC, and the obtained thermograms are shown in Figure $2(\mathrm{a}-\mathrm{d})$. Softisan ${ }^{\circledR} 154$ thermogram gave an endothermic melting peak at $51.69{ }^{\circ} \mathrm{C}$ and enthalpy of $-0.82 \mathrm{Jg}^{-1}$. T. conophorum oil exhibited two endothermic peaks, corresponding to melting $\left(89.61{ }^{\circ} \mathrm{C}\right)$ and decomposition $\left(257.47{ }^{\circ} \mathrm{C}\right)$ events, respectively, with enthalpy of $-3.22 \mathrm{Jg}^{-1}$. When the lipid matrix was prepared using the solid and liquid lipids, the thermal properties of the matrix included an endothermic melting peak at $85.22{ }^{\circ} \mathrm{C}$ and enthalpy of $-8.56 \mathrm{Jg}^{-1}$ with the total disappearance the decomposition peak of the oil. The implication is that the molecular interaction between the lipid materials resulted in rearrangement leading to high disorderliness in the lattice structure of the lipid matrix with improved drug encapsulation and holding capacity. It is considered that the PEG chains in the matrix might have lowered the glass transition temperature, $\mathrm{Tg}$ of the lipids, probably due to its plasticizing effect and molecular rearrangements in the lipids lattice structure [44]. DHA thermogram showed no endothermic melting peak but an exothermic onset melting point at $179.5^{\circ} \mathrm{C}$ which peaked at $189.5^{\circ} \mathrm{C}$ with enthalpy of $-13.58 \mathrm{Jg}^{-1}$ showing its crystallinity and purity. Incorporation of DHA in the lipid matrix did not show the melting exotherm of DHA but recorded an endothermic melting peak at $87.46{ }^{\circ} \mathrm{C}$ with an enthalpy of $-8.63 \mathrm{Jg}^{-1}$.

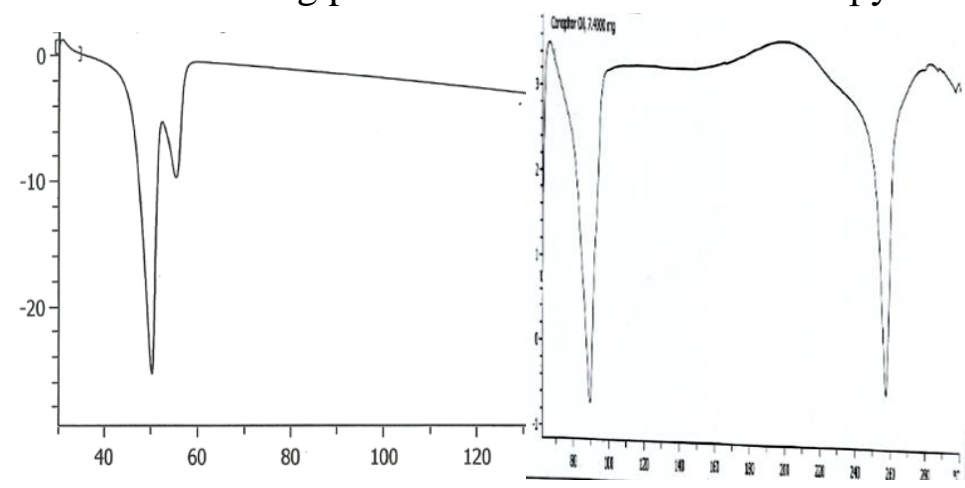

(a)

(b)

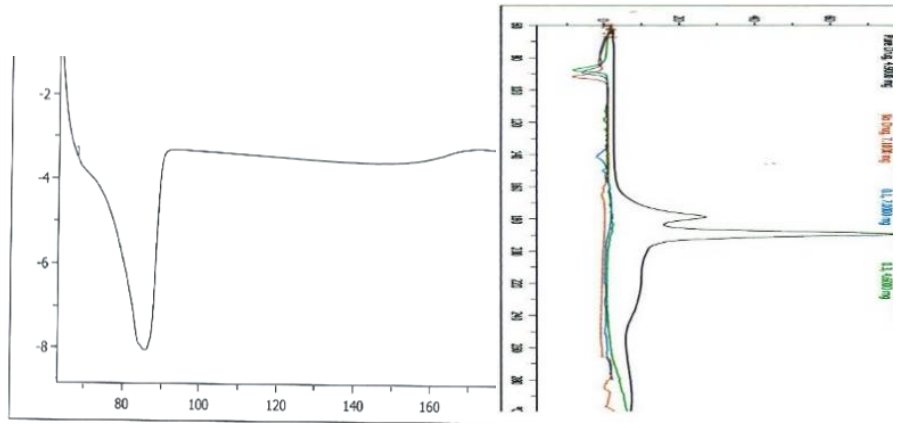

(c)

(d)

Figure 2. DSC thermograms of (a) Softisan ${ }^{\circledR} 154$ (b) Tetracarpidium conophorum oil (c) PEGylated lipid matrix (d) thermograms of dihydroartemisinin (dark color), placebo NLC (bright-red color), representative PEGylated DHA-NLC (blue color), and non-PEGylated unloaded NLC (dark-red color) in superposition.

A similar outcome was observed for the non-PEGylated NLC, indicating adequate entrapment of DHA within the matrix core in amorphous form; in other words, DHA was properly solubilized and encapsulated in the NLC. The absence of the exothermic peak of DHA in the loaded NLC, indicates profound stability, compatibility, and solubilization of the drug in the formulation. This is in agreement with an earlier report [28]. Furthermore, amorphization 
of DHA in the nanoformulations would likely promote its controlled release from the NLC without any burst effect.

\subsection{FT-IR analysis.}

FT-IR spectroscopy is used to analyze distortions in atomic distances, molecular interactions, and detect the presence of functional groups through a comparison of measured stretching or bending vibrations between standard and test spectra [45]. Therefore, any changes in the absorption bands of functional groups due to chemical shift, disappearance, or formation of entirely new bands suggest possible molecular interaction. Figure 3 (a-c) shows the FT-IR spectra of DHA and representative NLC. In the DHA spectrum, high wavenumbers of 3718.5, $3446.5,3348,3248.0 \mathrm{~cm}^{-1}$ which correspond to $-\mathrm{OH}$ stretching vibration, mid-wave numbers of 2990.0, 2847.0, $2663.3 \mathrm{~cm}^{-1}$ correspondings to symmetric $\mathrm{C}-\mathrm{H}$ stretch with methyl bending modes overtones, $1396.9,1643.2 \mathrm{~cm}^{-1}$ correspondings to $\mathrm{C}-\mathrm{O}$ stretching vibration, and 792.0 , $918.4 \mathrm{~cm}^{-1}$ correspondings to $\mathrm{C}-\mathrm{O}-\mathrm{O}-\mathrm{C}$ stretching vibration characteristic for endoperoxide ring in artemisinins, were detected. In comparison, the FT-IR spectrum of F1 (representative NLC batch) revealed $-\mathrm{OH}$ stretching, symmetric $\mathrm{C}-\mathrm{H}, \mathrm{C}-\mathrm{O}$, and $\mathrm{C}-\mathrm{O}-\mathrm{O}-\mathrm{C}$ bending vibrations with high wave and mid-wave numbers 3805.2, 3521.8, 3318.6; 2933.9, 2806.6, 2693.1; $1935.0 ; 1165.2 \mathrm{~cm}^{-1}$ as already described for DHA. This proves that the endoperoxide ring of DHA was not tampered with in the nanoformulation, thereby ensuring that its bioactivity was retained. Conversely, these wavenumbers were not present in the unloaded NLC (batch F4), indicating that the formulation does not contain DHA.

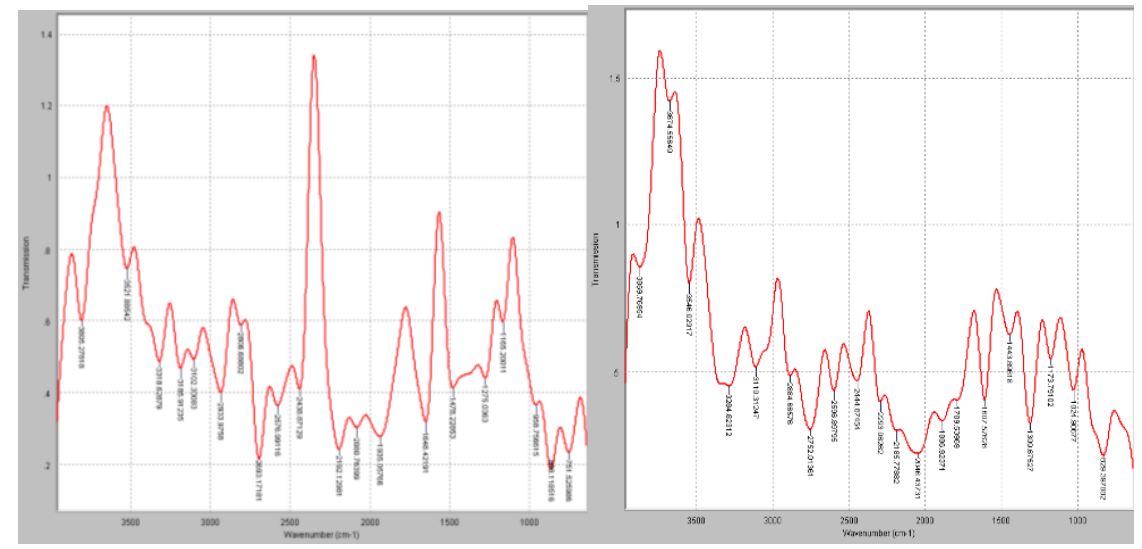

(a)

(b)

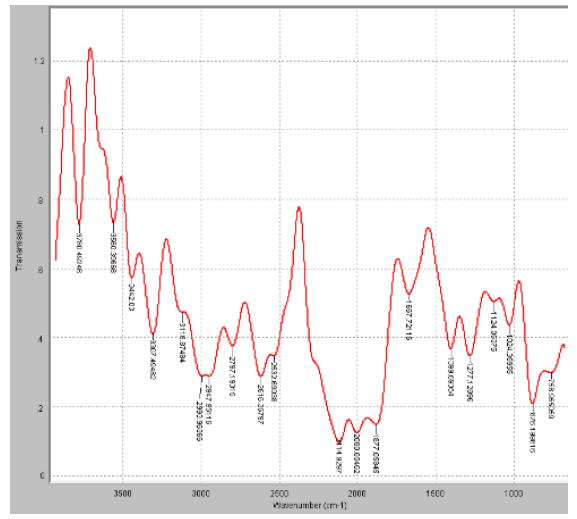

(c)

Figure 3. FT-IR spectra of (a) Dihydroartemisinin (b) Batch F1 DHA-loaded NLC formulation, which is PEGylated (c) Batch F4 unloaded NLC formulation which is PEGylated. 
Generally, the FT-IR spectra from the study suggest no incompatibility between DHA and other formulation excipients used in the NLC. Furthermore, the result of the study revealed that PEGylation did not result in molecular interaction since there was no shift, disappearance, or appearance of novel fingerprints in both PEGylated and non-PEGylated NLC.

\section{6. $X$-ray diffraction $(X R D)$.}

$\mathrm{XRD}$ is a technique applied in evaluating changes in the polymorphic profile and molecular orientation of drug and lipid molecules which may affect the biopharmaceutical properties of biomolecules [46]. DHA is a crystalline drug and showed characteristic crystalline peaks. Therefore, XRD could be used to study any changes in its crystallinity or its precipitation in an amorphous form, which is necessary for improved solubility [47]. The X-ray diffractograms are shown in Figure $4(\mathrm{a}-\mathrm{d})$. The X-ray diffractogram of Softisan ${ }^{\circledR} 154$ revealed characteristic high-intensity diffraction fingerprints at $(2 \theta) 21^{\circ}, 22^{\circ}$, and $24^{\circ}$. X-ray diffractogram of the lipid matrix recorded sharp fingerprints at $(2 \theta) 19^{\circ}, 23^{\circ}$, and $24^{\circ}$ respectively. The characteristic high-intensity diffraction peaks observed in Softisan ${ }^{\circledR} 154$ might be due to the presence of esters of low chain fatty acids $\left(\mathrm{C}_{10}-\mathrm{C}_{18}\right)$ and the absence of polymorphic forms in the solid lipid. In addition, there was the presence of other medium and low-intensity reflections indicating the crystalline nature of Softisan ${ }^{\circledR} 154$. The high-intensity diffraction fingerprints recorded in the x-ray diffractogram of Softisan ${ }^{\circledR} 154$, which were missing in the XRD profile of the lipid matrix, might be due to the molecular integration of the fatty acid chains in the solid lipid and T. conophorum oil resulting in a disordered and widened crystal lattice structure of the lipids [14]. The XRD structures of pure DHA presented several strong, sharp peaks at $(2 \theta) 7.5^{\circ}, 9.5^{\circ}, 11.5^{\circ}, 12.5^{\circ}, 17.0^{\circ}, 18.0^{\circ}, 19.5^{\circ}, 20.0^{\circ}, 25.0^{\circ}$, and $30.0^{\circ}$ in addition to the presence of minor reflections of medium and low intensities, indicating that DHA used was crystalline, and in conformity with an earlier report [48]. X-ray diffractograms of the DHA-loaded formulations showed low intensity and diffused peaks without the identified sharp characteristic fingerprints of DHA. This could be attributed to the amorphization of DHA within the molecules of the lipid matrix, indicating that DHA was completely entrapped and solubilized in the matrix system $[49,50]$. Amorphization of DHA ensured that it was retained or entrapped within the lipid matrix milieu, and this proves that DHA attained sufficient solution stability in the PEGylated lipid matrix system.

\section{7. pH measurement.}

To determine that the nanogels were suitable for application to the skin, their $\mathrm{pH}$ values were ascertained. Measured $\mathrm{pH}$ values of the nanogels shown in Figure 5 revealed that all the gels had $\mathrm{pH}$ in the range of $4.40-5.25$ after $24 \mathrm{~h}$, with insignificant ( $\mathrm{p}>0.05$ ) flip-flops observed following reassessment after 30 and 90 days of storage indicating good storage stability property. The plain gel also gave a normal $\mathrm{pH}$ range of $4.0-4.7$. However, the $\mathrm{pH}$ of the nanogels is within the range of the $\mathrm{pH}$ of normal skin $(4-5.5)$. This means that the gels have $\mathrm{pH}$ values within acceptable limits for topical application and might maintain normal skin homeostasis without producing any cutaneous reactions on long-term skin application. The obtained $\mathrm{pH}$ values will also maintain drug stability as it has been shown that DHA has maximum stability within the $\mathrm{pH}$ range of $2-6$ and is highly unstable at alkaline $\mathrm{pH}$ values [51]. DHA is chemically fragile at high $\mathrm{pH}$ values and undergoes ring-opening and rearrangement, yielding deoxyartemisinin, an inert end product [52]. 


\subsection{Spreadability.}

Placing load (weight) on the nanogels increased the spread area of all the gels' batches. Spreadability measurement is vital for enhanced adherence to a formulation and to ensure uniform dose application on the skin.

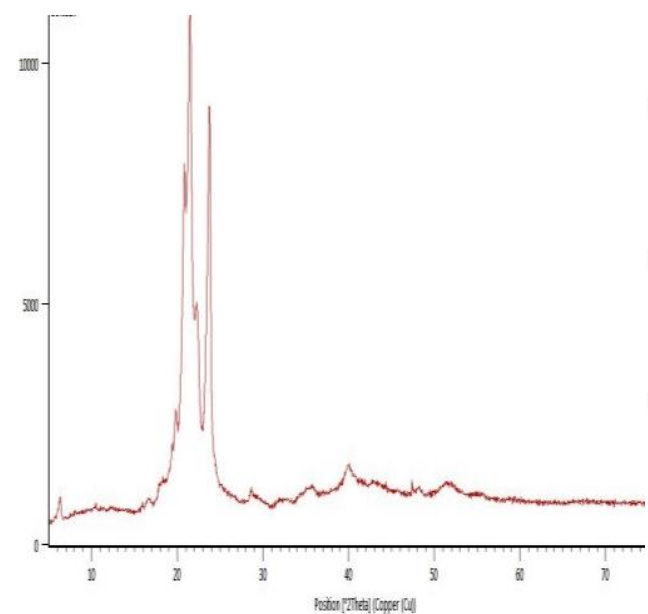

(a)

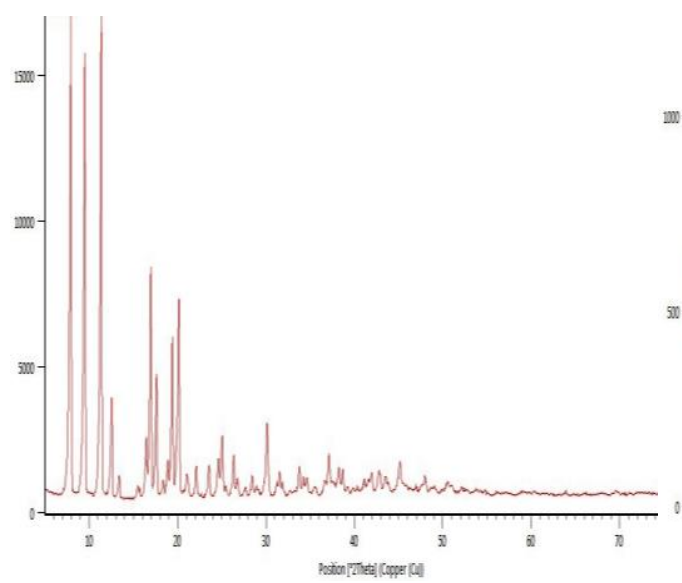

(c)

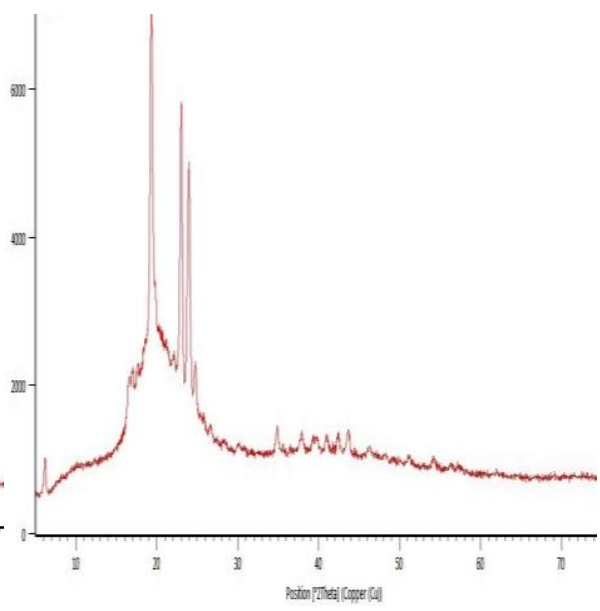

(b)

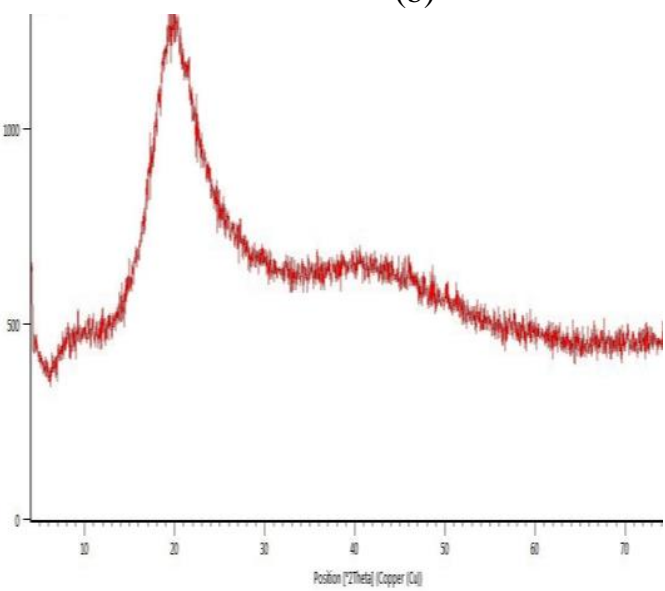

(d)

Figure 4. X-ray diffractograms of (a) Softisan ${ }^{\circledR} 154$ (b) lipid matrix (c) pure dihydroartemisinin, DHA, and (d) DHA-loaded nanostructured system

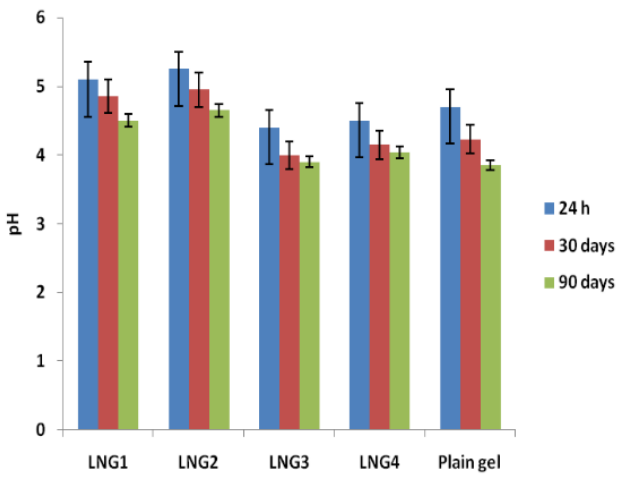

Figure 5. $\mathrm{pH}$ of nanostructured systems and plain gels recorded within 24 hours, 30, and 90 days after formulation. Data shown as mean $\mathrm{pH} \pm$ standard deviation (SD) where $\mathrm{n}=3$. LNG1, 2, and 3 are lipid nanogels (LNG) containing 0.1, 0.2, and $0.3 \%$ w/w DHA-loaded NLC, while LNG4 was formulated using placebo NLC.

The plain gel does not contain NLC.

The result of the spreadability analysis shown in Table 3 indicates that the nanogels generally have excellent spreadability values. This might be due to the good gelling property of the gelling agent, hydroxypropyl cellulose (HPC), used in the formulations. 
HPC is a hydroxy-substituted cellulose derivative that has been reported to be a good excipient in pharmaceutical, food, cosmetic and topical formulations such as transdermal patches and ophthalmic preparations. In addition, it is nonionic, nonreactive, and non-toxic [53, 54]. The result showed that the spreadability of the nanogels ranged from $400 \pm 0.18 \%$ to 520 $\pm 0.14 \%$. This is not quite comparable with the plain gel with a high spreadability value of 660 $\pm 0.05 \%$, probably due to the DHA-nanoparticles content of the nanogels. In addition, the excellent spreadability recorded indicates that HPC is very compatible with the oil and other excipients used in the formulations, and the gels are easily spreadable in the presence of minimal shear. Therefore, the result satisfies the hypothesis that the gels will be suitable for skin application and might favor improved topical anti-inflammatory activity of DHA since they could be easily spread on the skin.

Table 3. Physicochemical properties of the NLC-engrossed gels.

\begin{tabular}{l|c|c|c|c|c} 
Formulation & $\begin{array}{c}\text { Drug content } \\
(\mathbf{\%})\end{array}$ & Drug content $(\boldsymbol{\%})$ & $\begin{array}{c}\text { Spreadability (\% } \\
\mathbf{\pm} \text { SD) }\end{array}$ & Occlusivity (F) & \\
\hline & $\mathbf{2 4} \mathbf{h}$ & $\mathbf{9 0 ~ d a y s}$ & & $\mathbf{2 4} \mathbf{h}$ & $\mathbf{4 8 ~ h}$ \\
\hline LNG1 & $83.87 \pm 0.0$ & $81.71 \pm 1.2$ & $400.0 \pm 0.18$ & 55 & 60 \\
\hline LNG2 & $92.01 \pm 0.1$ & $90.21 \pm 3.1$ & $520.0 \pm 0.24$ & 65 & 64 \\
\hline LNG3 & $99.41 \pm 0.1$ & $96.08 \pm 1.1$ & $450.0 \pm 0.06$ & 68 & 69 \\
\hline LNG4 & *NAPI & *NAPI & $620.0 \pm 0.14$ & 40 & 42 \\
\hline Plain gel & *NAPI & *NAPI & $660.0 \pm 0.05$ & 50 & 51
\end{tabular}

LNG1, 2, and 3 are lipid nanogels (LNG) containing 0.1, 0.2, and 0.3\%w/w DHAloaded NLC, while LNG4 was formulated using placebo NLC. The plain gel does not contain NLC. *NAPI means no active pharmaceutical ingredient

\subsection{Occlusivity measurement.}

For the nanogels to have satisfactory topical anti-inflammatory performance, they must have the ability to create thin films with very narrow interspaces between their molecules, which will prevent transepidermal water loss and promote skin hydration. Improved skin hydration leads to opening corneocytes tight junctions with better drug permeation of the skin [46]. It could be seen from the result in Table 3 that after $24 \mathrm{~h}$, the F-value of plain gel was 50 $\%$, the F-values of the DHA-NLC loaded nanogels ranged from 55 - $68 \%$, while the F-value of unloaded nanogel was $40 \%$. Similar, DHA-NLC loaded nanogels recorded F-values ranging from $60-69 \%$, the F-value of unloaded nanogel was $42 \%$, while the F-value of the plain gel was $51 \%$, after $48 \mathrm{~h}$. The result showed that the gels maintained a reliable semisolid consistency which might lead to reduced transepidermal water loss from the skin surface on application leading to increased hydration and satisfactory deposition of DHA into the skin [28]. This essential attribute will also be of immense benefit in alleviating some adverse effects on the skin, such as itching, dryness, and scaling [55, 56].

\subsection{Drug content.}

The percentage drug content for DHA-loaded NLC-based gels shown in Table 3 revealed that drug entrapment of the nanogels increased with increased drug loading. The drug content efficiency ranged from $83 \%$ (for nanogel containing $0.1 \% \mathrm{w} / \mathrm{w}$ of DHA) - $99 \%$ (for nanogel containing $0.3 \% \mathrm{w} / \mathrm{w}$ DHA). This corroborates our earlier observation on the primary nanostructured systems. It indicates that the HPC-based gel system provided enough space for solubilization and entrapment of the drug-loaded nanocarrier system without any leakage 
resulting in excellent overall percentage drug content. In addition, the result showed that the high solubility of DHA in the liquid lipid tended to increase the drug entrapment as a result of favorable molecular interaction between DHA and T. conophorum oil; and thus, influenced drug content efficiency.

\subsection{Viscometry.}

Since flow behavior influences drug release from topical delivery systems as well as affects patient acceptance and compliance [57], the viscosities of the nanogels were screened to ascertain their extrudability or pourability from the container, and flowability, which was hinted by the measured spreadability values. Deposition and/or penetration of DHA across the skin could also be determined through viscometry. The DHA nanogels should possess appropriate viscosities, facilitating drug release for enhanced establishment and maintenance of contact with the skin [37]. The result of the viscometric evaluation of the nanogels and the plain gel shown in Figure 6 indicates that generally, the semisolid preparations are viscous with values ranging from approximately $3000-7000 \mathrm{mPa}$.s. This is probably due to the high viscosity of the gelling agent. However, it was observed that the gels are strongly pseudoplastic (they exhibited decreased viscosity from 7000 - $3000 \mathrm{mPa} . \mathrm{s}$ with increased shearing from 6 $60 \mathrm{rpm}$ ). Thus, the applied shearing force caused molecules of the gels to align themselves in the direction of flow, leading to destabilization and alteration of their network structures. The alignment will result in reduced internal friction between the molecules themselves with the ability to spread easily on the skin and ultimately leading to shear-thinning and probable significant thixotropy, which is a desirable characteristic of non-Newtonian systems [24, $58,59]$.

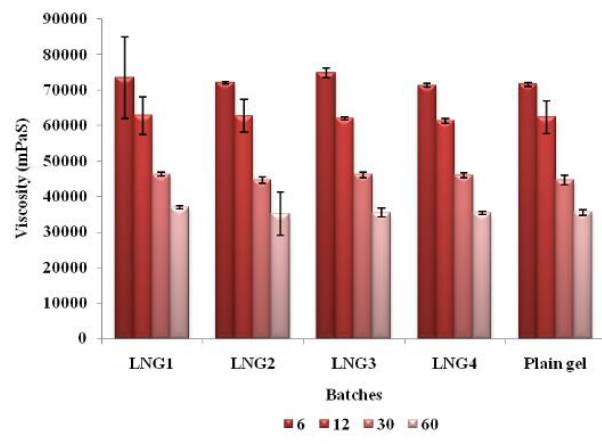

Figure 6. Viscosity of lipid nanogels of dihydroartemisinin. Key: LNG 1, 2, 3 are lipid nanogels (LNG) containing 0.1, 0.2, and $0.3 \% \mathrm{w} / \mathrm{w}$ DHA-loaded NLC. LNG 4 is a lipid nanogel containing placebo NLC.

Values represent Mean \pm standard deviation $(n=3)$.

The recorded viscosity profile is not a disadvantage to the nanogels because it will favor better and prolonged skin adhesion and retention of the gels [60]. It was obvious from Figure 6 that increased shearing yielded consistently decreased viscosities of the plain gel and nanogels (PEGylated and non-PEGylated) with insignificant ( $p>0.05)$ difference in the recorded data but significant $(\mathrm{p}<0.05)$ increase in the recorded torques. However, the minor differences observed could be attributed to the diverse formulation compositions of the nonNewtonian structures.

\subsection{In vitro release and kinetic mechanism of release.}

The membraneless model was adapted in this study because it allows the release medium to be in direct contact with the gels to mimic use conditions and predict the actual 
amount of DHA released from the nanogels in the medium. The in vitro release profile is presented in Figure 7a. From the result, it is clearly seen that the DHA-loaded NLC (F3) showed an initial burst in the first $2 \mathrm{~h}$ exhibiting faster release of drug $(90.53 \pm 0.95 \%$ in $24 \mathrm{~h})$ compared with the nanogels, which released much more slowly in $24 \mathrm{~h}$. This could be attributed to the high rate of hydration, solubilization, non-PEGylation, and diffusion of free DHA into the release medium without encountering any diffusion barrier provided by either the PEG4000 chains or the network-like matrix structure of HPC [30, 61, 62]. However, it is exciting to note that all the nanogel systems (LNG1 - LNG3) exhibited a slow release profile of the drug (LNG1 $-45.01 \pm 1.2 \%$, LNG2 $-56.52 \pm 0.33 \%$, and LNG3 $-64.29 \pm 1.1 \%$ ) throughout $24 \mathrm{~h}$ indicating sustained-release effect. The sustained release of DHA from the nanogels could be attributed to the slow hydration and diffusion of DHA from the nanostructured systems due to the presence of the hydroxypropyl cellulose matrix. It could also be attributed to PEGylation, which extends the residence time of the drug before it is released in the medium. This result indicates that the nanogels can better reservoir systems for DHA than the NLC with a prolonged release profile [63]. The advantage of the sustained release profile of the DHA-NLC gels is that it would prevent rapid drug exposure to the skin, thereby evading possible toxicity effects, especially when applied on open or exfoliated skin. The gradual drug release indicates that the drug was not localized on the gel surface as it was properly entrapped in the core of the polymeric gelling material and dispersed in the gel matrix. Furthermore, it was found out that the controlled release property of the nanogels was not influenced by the increase in drug content as LNG1 containing > $80 \%$ of DHA showed the best-controlled release profile than LNG3, which contains about $99 \%$ of DHA. Thus, LNG1 gel was found to have the best in vitro release profile and displayed the best sustained-release property than LNG2 and 3 gels. However, since it has been known that drug release from lipid nanodispersions is influenced by several parameters, including nature of lipids, drug solubility in lipids, partition coefficient, and surface modification [30,64], it is possible that PEGylation might be responsible for the excellent controlled release of DHA from the nanogels, especially LNG1 and LNG2 which were formulated using PEGylated DHA-NLC in comparison to LNG3 which contains nonPEGylated NLC.

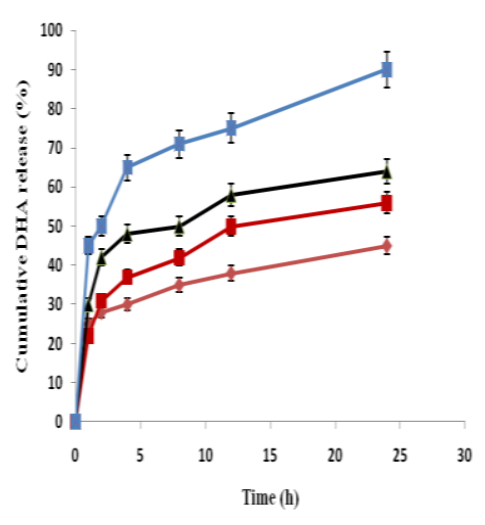

(a)

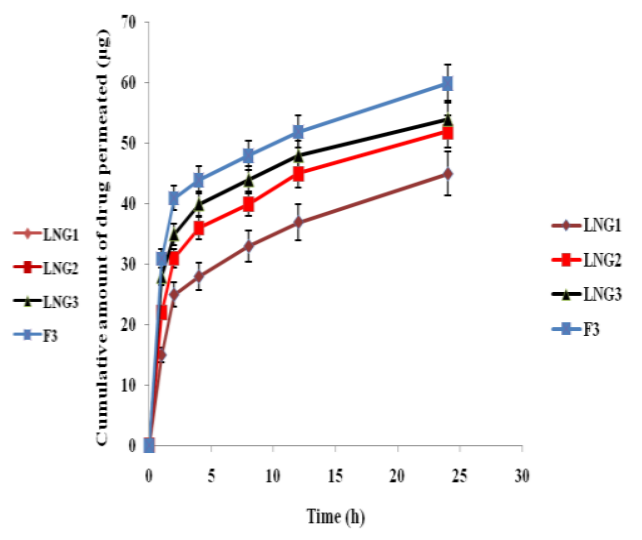

(b)

Figure 7. Release curves showing (a) cumulative in vitro release for the DHA-loaded NLC gels (LNG1-LNG3) and DHA-loaded NLC (F3), and (b) ex vivo skin permeation of DHA from nanogels (LNG1 - 3) against DHAloaded NLC (F3). Values are expressed as Mean \pm standard deviation $(n=3)$.

The kinetic study revealed that the nanogels and the DHA-loaded NLC followed the Higuchi square root of the time model of release. When the correlation coefficients $\left(r^{2}\right)$ of all the test samples were measured as shown in Table 4, the Higuchi model recorded higher $r^{2}$ than 
the $r^{2}$ of zero and first-order models. Analysis of the drug release mechanism applying the Korsmeyer-Peppas showed that the release exponent ' $n$ ' values (which characterize the drug release mechanism) were within the range of $0.6723-0.7915$. Therefore, it could be inferred that the nanogels and the NLC underwent a non-Fickian (anomalous) diffusion mechanism controlled mainly by diffusion rate and corrosion or erosion of the matrix system of the samples for sufficient drug release.

Table 4. Drug release kinetics of DHA-loaded NLC gels and DHA-loaded NLC.

\begin{tabular}{l|c|c|c|c|c}
\multirow{2}{*}{ Formulation } & Zero order & First order & \multicolumn{2}{c}{ Higuchi } & \multicolumn{2}{c}{ Korsmeyer-Peppas } \\
\hline LNG1 & $\mathbf{r}^{\mathbf{2}}$ & $\mathbf{r}^{\mathbf{2}}$ & $\mathbf{r}^{\mathbf{2}}$ & $\mathbf{r}^{\mathbf{2}}$ & $\mathbf{N}$ \\
\hline LNG2 & 0.675 & 0.967 & 0.988 & 0.898 & 0.791 \\
\hline LNG3 & 0.752 & 0.853 & 0.997 & 0.467 & 0.650 \\
\hline F3 & 0.876 & 0.885 & 0.991 & 0.729 & 0.672 \\
\hline
\end{tabular}

LNG1 - 3 are DHA-loaded NLC gels; F3 is non-PEGylated DHA-loaded NLC; $r^{2}$ is squared correlation coefficient; ' $n$ ' is drug release exponent in the Korsmeyer-Peppas release model

\subsection{Ex vivo skin permeation.}

Figure $7 \mathrm{~b}$ shows ex vivo skin permeation profiles of the DHA-loaded NLC gels and the representative DHA-loaded NLC (F3). An equivalent amount of the formulations containing known concentrations of DHA was used in this study to more closely simulate use conditions. After topical application, interpersonal differences in drug permeation are affected by the physicochemical characteristics of the drug and biological factors of the skin, such as degree of hydration and age [65]. DHA permeated the skin throughout $24 \mathrm{~h}$ from all the test samples at varying degrees. From the result, drug flux was faster from the DHA-NLC (F3) (10.98 \pm $\left.0.11 \mu \mathrm{g} / \mathrm{cm}^{2} / \mathrm{h}\right)$ with time than from the NLC-engrossed gels $(5.12 \pm 0.1,7.23 \pm 0.92$, and 8.85 $\pm 0.5 \mu \mathrm{g} / \mathrm{cm}^{2} / \mathrm{h}$ for LNG1, LNG2, and LNG3 respectively). In addition, the amount of permeated drug from F3 was slightly higher than the nanogels at a particular time point, in line with earlier observation already described for in vitro release study. This could be due to the liquid lipid ( $T$. conophorum oil) used in the formulation, which further solubilized and enhanced drug permeation into the skin. Furthermore, it could be inferred that drug permeation from DHA-NLC was far greater than from the DHA-NLC gels due to the absence of PEGylation and gelation of the test DHA-NLC. These characteristics (PEGylation and gelation) might have extended the residential time and provided an extra trafficking interface for the nanogels resulting in prolonged drug release that will make it possible, acceptable, and meaningful for the intervals of therapy using DHA nanogels to be extended. This is in agreement with literature that indicates that the flux and permeability of drugs from nanogels are affected by membrane properties such as effective surface area, pores, thickness, and the properties of the nanoparticles and the gel [66]. The substantial amount of drug permeated could be due to the small particle size of the nanostructured systems, which might have created an increased surface area for enhanced drug transportation into the skin aided by improved skin partitioning [67]. These results confirm that DHA-NLC gels can penetrate the skin.

Interestingly, there was an insignificant difference $(p>0.05)$ in the amount of drug permeation between the nanogels (though drug permeation progressed as follows: LNG1 $<$ LNG2<LNG3), demonstrating that the encapsulation of the lipid nanoparticles of DHA using HPC polymer was successful. Therefore, DHA nanogels were successfully developed as a novel formulation for topical application and suitable for therapy. From the result, it could be concluded that formulation of DHA-NLC as nanogels might be vital in improving DHA 
trafficking into the skin, producing targeted sustained release activity, without bolus access to internal tissues and toxicity compared to plain NLC.

\subsection{Skin tolerance test.}

The skin tolerance test is an important study for topical formulations, and topical formulations should possess a high degree of skin tolerability for enhanced compliance during use $[67,68]$. Thus, it is very vital to determine the skin tolerance potential of the formulated DHA-NLC and plain gels. The result showed that both the DHA-NLC gel and the plain gel samples produced no marked or signs of morphological changes on the normal rat skin such as erythema, papules, wrinkling, and dermatitis after $72 \mathrm{~h}$ of application, indicating no potential to induce irritation, hypersensitivity, or toxicity reactions. However, the rat that received the irritant formaldehyde solution produced obvious skin disruptions with severe erythema and possible inflammatory cellular infiltrations. The good skin tolerability of the nanogels could be due to the biocompatibility of the excipients used in preparing the NLC and the gels, especially Softisan ${ }^{\circledR} 154$, T.conophorum oil, the nonionic surfactants, PEG 4000, and HPC, which are generally regarded as safe (GRAS) excipients. The study showed that rat skin tolerated the DHA-NLC gels without any weeping surface and, thus, safe to be applied topically. In addition, the result of this study supports the hypothesis that PEGylated lipid matrix can be used to develop nanostructured lipid carriers containing T. conophorum oil, which, when engrossed in a biocompatible polymer like hydroxypropyl cellulose (HPC), gives nanogels for safe and effective dermal delivery of dihydroartemisinin (DHA).

\subsection{Topical anti-inflammatory activity.}

Paw swelling is an important indicator in an experiment to evaluate the degree of inflammation. An anti-inflammatory study aimed to evaluate the formulations' ability to resolve localized inflammatory conditions in comparison with the controls and commercial anti-inflammatory gels, and the result is presented in Figure 8. Following induction of paw inflammation using egg albumin, group 1 rats treated with placebo gel produced a slight reduction in oedema $(90 \pm 0.1 \%)$ within the $5^{\text {th }} \mathrm{h}$ of the first day, which gradually increased on day 2 , then remained unchanged at $95.1 \pm 0.18 \%$ throughout the remaining study duration. The slight reduction might be due to the initial transient delay of the inflammatory mediators to produce a full response at the target site, and the non-reduction of oedema indicated the inefficiency of the placebo gel. Group 2 rats treated with batch F3 NLC produced sustained and better anti-inflammatory activity than the placebo gel. The anti-inflammatory effect of this group emerged slowly at the $2^{\text {nd }} \mathrm{h}(82.2 \pm 0.3 \%)$ of day 2 . This effect was maintained significantly $(\mathrm{p}<0.05)$ until the last hour of day 7 when $40.3 \pm 0.7 \%$ oedema reduction was recorded. This confirms that DHA can produce anti-inflammatory activity, and the PEGylated NLC carrier system might be a desirable vehicle for topical and sustained drug delivery. For experimental rats in groups 3,4 , and 5 that received LNG1 -3 , a significant $(\mathrm{p}<0.05)$ antiinflammatory effect was recorded from the $1^{\text {st }} \mathrm{h}$ of day 1 post-induction of inflammation and progressed steadily to the last day of the study. While LNG1 recorded $28.3 \pm 0.2 \%$ reduced paw oedema, LNG 2 and 3 recorded $19.1 \pm 1.1$ and $17.0 \pm 0.5 \%$ respectively, oedema reduction at the $8^{\text {th }} \mathrm{h}$ of day 7 of the study. The sustained anti-inflammatory effect consolidates the outcomes of the in vitro release and ex vivo permeation studies of the gels. It was observed that reduction of paw oedema of the gels was dependent on drug loading, and even more interesting 
was the observation that LNG3 formulated from batch F3 NLC produced better $(p<0.05)$ resolution of inflammation than the parent nanoformulation, perhaps this discrepancy might be related to its better occlusivity and consistency resulting in higher permeation and retention of DHA in the skin. Reduced paw inflammation produced by group 6 rats that received the market brand was similar and comparable to the LNG1 - 3 though the former did not follow a sustained release pattern. These results have shown that DHA-loaded NLC gel could be effectively used for the treatment of inflammation.

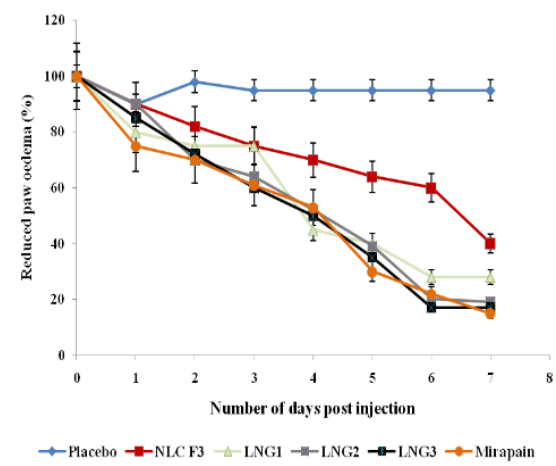

Figure 8. Effects of different treatments on paw volume of rats after topical application: Placebo (formulated using unloaded NLC), NLC F3 (nanostructured lipid carrier loaded with $0.3 \%$ w/w of DHA), LNG1 - 3 (gels formulated using DHA-loaded NLCs loaded with $0.1-0.3 \%$ w/w of DHA), Mirapain ${ }^{\circledR}$ (commercial brand). Values are expressed as mean \pm standard deviation $(n=3)$.

\subsection{Storage stability study.}

In the design of novel dosage forms, storage stability study is vital because it provides very useful data regarding the ability of the formulation to retain its quality and efficacy throughout its shelf-life $[38,69]$. When the nanogels were visually examined, they were stable without any sign of phase separation, precipitation, or discoloration. In addition, there were insignificant changes $(\mathrm{p}>0.05)$ in drug content as presented in Table 3 when the nanogels were stored at ambient $\left(25 \pm 2{ }^{\circ} \mathrm{C} / 60 \pm 5 \% \mathrm{RH}\right)$ and elevated $\left(40 \pm 2{ }^{\circ} \mathrm{C} / 75 \pm 5 \% \mathrm{RH}\right)$ temperatures, suggesting that the nanogels could be stored optimally at room or elevated temperatures and will retain their integrity when used in tropical conditions $\left(30-40{ }^{\circ} \mathrm{C}\right.$ and $60-75 \%$ humidity). There is also a very high level of confidence that the nanogels will maintain their integrity by retaining a minimum of $90-95 \%$ of DHA throughout their shelf-lives as prescribed by the current international pharmaceutical law [70].

\section{Conclusions}

For the first time, this study reports the systematic development of surface-modified DHA-loaded NLC engrossed gels for topical treatment of inflammation. The NLC was formulated using a lipid matrix comprising Softisan ${ }^{\circledR} 154$ and T. conophorum oil mix, which was surface modified using PEG4000. The hot homogenization technique was successfully used to formulate the DHA-loaded NLC with good and reliable physicochemical properties. DHA-loaded NLC gels were physically stable at ambient and elevated temperature and humidity conditions and showed efficient occlusion, $\mathrm{pH}$, spreadability properties. DHA-loaded NLC gels showed sustained and enhanced skin permeation, deposition, and retention, thus giving the nanogels the potential to form drug reservoirs in the skin from which DHA could be docked in deeper layers of the skin for resolution of inflammation. In addition to good skin tolerability, these excellent preclinical properties provide the basis for the need for clinical 
trials on human volunteers and possible scale-up. Thus, it can be concluded that PEGylated NLC has proven to be an ideal nanocarrier system with controlled release properties and may benefit the formulation of gels containing DHA for topical treatment of localized inflammation.

\section{Funding}

This research received no external funding.

\section{Acknowledgments}

The authors thank Greenlife Pharmaceuticals Ltd, Lagos, Nigeria, for the free gift of dihydroartemisinin pure sample. They also thank Fa.Condea Chemie GmbH, Germany, for the free gift of Softisan ${ }^{\circledR} 154$. We acknowledge BASF SE, Ludwigshafen, Germany, for supporting this study with the provision of Kolliphor ${ }^{\circledR} \mathrm{P} 188$. We thank Carl Roth $\mathrm{GmbH}$ and Co. KG, Karlsruhe, Germany for the gift of Polyethylene glycol 4000 (PEG 4000). The authors thank Nippon Soda Chemical Company Ltd., Tokyo, Japan, for the kind donation of Hydroxypropyl cellulose (HPC) powder.

\section{Conflicts of Interest}

The authors declare no conflict of interest.

\section{References}

1. Yimer, T.; Birru, E.M.; Adugna, M.; Geta, M.; Emiru, Y.K. Evaluation of analgesic and anti-inflammatory activities of $80 \%$ methanol root extract of Echinops kebericho M. (Asteraceae). J inflamm Res. 2020, 13, 647-658, https://doi.org/10.2147/JIR.S267154.

2. Kuropakornpong, P.; Itharat, A.; Panthong, S.; Sireeratawong, S.; Ooraikul, B. In vitro and in vivo antiinflammatory activities of Benjakul: A potential medicinal product from Thai traditional medicine. Evid Based Complement Alternat Med 2020,2020, 1-8, https://doi.org/10.1155/2020/9760948.

3. Sánchez, A.B.; Calpena, A.C.; Soriano, J.L.; Gálvez, P.; Clares, B. Anti-inflammatory nanomedicines: what does the future hold? Nanomedicine 2020, 15, 1357-1360,https://doi.org/10.2217/nnm-2020-0064.

4. Cooper, C.; Chapurlat, R.; Al-Daghri, N.; Herrero-Beaumont, G.; Bruyère, O.; Rannou, F.; Roth, R.; Uebelhart, D.; Reginster, J.-Y. Safety of Oral Non-Selective Non-Steroidal Anti-Inflammatory Drugs in Osteoarthritis: What Does the Literature Say? Drugs \& Aging 2019, 36, 15-24, https://doi.org/10.1007/s40266-019-00660-1.

5. Xia, M.; Liu, D.; Liu, Y.; Liu, H. The Therapeutic Effect of Artemisinin and Its Derivatives in Kidney Disease. Frontiers in Pharmacology 2020, 11,https://doi.org/10.3389/fphar.2020.00380.

6. Shi, C.; Li, H.; Yang, Y.; Hou, L. Anti-Inflammatory and Immunoregulatory Functions of Artemisinin and Its Derivatives. Mediators of Inflammation 2015, 2015, 1-7, https://doi.org/10.1155/2015/435713.

7. Zech, J.; Dzikowski, R.; Simantov, K.; Golenser, J.; Mäder, K. Transdermal delivery of artemisinins for treatment of preclinical cerebral malaria. International Journal for Parasitology: Drugs and Drug Resistance 2021, 16, 148-154,https://doi.org/10.1016/j.ijpddr.2021.05.008.

8. Zyad, A.; Tilaoui, M.; Jaafari, A.; Oukerrou, M.A.; Mouse, H.A. More insights into the pharmacological effects of artemisinin. Phytotherapy Research 2018, 32, 216-229,https://doi.org/10.1002/ptr.5958.

9. Zhang, T.; Zhang, Y.; Jiang, N.; Zhao, X.; Sang, X.; Yang, N.; Feng, Y.; Chen, R.; Chen, Q. Dihydroartemisinin regulates the immune system by promotion of CD8+ T lymphocytes and suppression of B cell responses. Science China Life Sciences 2020, 63, 737-749,https://doi.org/10.1007/s11427-019-95504.

10. Zhao, Y.G.; Wang, Y.; Guo, Z.; Gu, A.-d.; Dan, H.C.; Baldwin, A.S.; Hao, W.; Wan, Y.Y. Dihydroartemisinin Ameliorates Inflammatory Disease by Its Reciprocal Effects on Th and Regulatory $\mathrm{T}$ Cell Function via Modulating the Mammalian Target of Rapamycin Pathway. The Journal of Immunology 2012, 189, 4417-4425, https://doi.org/10.4049/jimmunol.1200919.

11. Zhang, X.; Qiao, H.; Liu, J.; Dong, H.; Shen, C.; Ni, J.; Shi, Y.; Xu, Y. Dihydroartemisinin loaded nanostructured lipid carriers (DHA-NLC): Evaluation of pharmacokinetics and tissue distribution after intravenous administration to rats. Die Pharmazie - An International Journal of Pharmaceutical Sciences 2010, 65, 670-678,https://doi.org/10.1691/ph.2010.0082. 
12. Wang, D.; Li, H.; Gu, J.; Guo, T.; Yang, S.; Guo, Z.; Zhang, X.; Zhu, W.; Zhang, J. Ternary system of dihydroartemisinin with hydroxypropyl- $\beta$-cyclodextrin and lecithin: Simultaneous enhancement of drug solubility and stability in aqueous solutions. Journal of Pharmaceutical and Biomedical Analysis 2013, 83, 141-148,https://doi.org/10.1016/j.jpba.2013.05.001.

13. Liu, K.; Dai, L.; Li, C.; Liu, J.; Wang, L.; Lei, J. Self-assembled targeted nanoparticles based on transferrinmodified eight-arm-polyethylene glycol-dihydroartemisinin conjugate. Scientific Reports 2016, 6, https://doi.org/10.1038/srep29461.

14. Umeyor, C.E.; Okoye, I.; Uronnachi, E.; Okeke, T.; Kenechukwu, F.; Attama, A. Repositioning miconazole nitrate for malaria: Formulation of sustained release nanostructured lipid carriers, structure characterization and in vivo antimalarial evaluation. Journal of Drug Delivery Science and Technology 2021, 61, https://doi.org/10.1016/j.jddst.2020.102125.

15. Souto, E.B.; Wissing, S.A.; Barbosa, C.M.; Müller, R.H. Development of a controlled release formulation based on SLN and NLC for topical clotrimazole delivery. International Journal of Pharmaceutics 2004, 278, 71-77,https://doi.org/10.1016/j.ijpharm.2004.02.032.

16. Subramaniam, B.; Siddik, Z.H.; Nagoor, N.H. Optimization of nanostructured lipid carriers: understanding the types, designs, and parameters in the process of formulations. Journal of Nanoparticle Research 2020, 22,https://doi.org/10.1007/s11051-020-04848-0.

17. Vaghasiya, H.; Kumar, A.; Sawant, K. Development of solid lipid nanoparticles based controlled release system for topical delivery of terbinafine hydrochloride. European Journal of Pharmaceutical Sciences 2013, 49, 311-322,https://doi.org/10.1016/j.ejps.2013.03.013.

18. Yang, X.; Zhao, L.; Almasy, L.; Garamus, V.M.; Zou, A.; Willumeit, R.; Fan, S. Preparation and characterization of 4-dedimethylamino sancycline (CMT-3) loaded nanostructured lipid carrier (CMT3/NLC) formulations. International Journal of Pharmaceutics 2013, 450, 225-234, https://doi.org/10.1016/j.ijpharm.2013.04.021.

19. Tiwari, S.; Mistry, P.; Patel, V. SLNs based on co-processed lipids for topical delivery of terbinafine hydrochloride. J Pharm Drug Dev. 2014,1, https://doi.org/10.15744/2348-9782.1.604.

20. Araújo, J.; Garcia, M.L.; Mallandrich, M.; Souto, E.B.; Calpena, A.C. Release profile and transscleral permeation of triamcinolone acetonide loaded nanostructured lipid carriers (TA-NLC): in vitro and ex vivo studies. Nanomedicine: Nanotechnology, Biology and Medicine 2012, 8, 1034-1041, https://doi.org/10.1016/j.nano.2011.10.015.

21. Cirri, M.; Bragagni, M.; Mennini, N.; Mura, P. Development of a new delivery system consisting in "drug in cyclodextrin - in nanostructured lipid carriers" for ketoprofen topical delivery. European Journal of Pharmaceutics and Biopharmaceutics 2012, 80, 46-53,https://doi.org/10.1016/j.ejpb.2011.07.015.

22. How, C.W.; Rasedee, A.; Manickam, S.; Rosli, R. Tamoxifen-loaded nanostructured lipid carrier as a drug delivery system: Characterization, stability assessment and cytotoxicity. Colloids and Surfaces B: Biointerfaces 2013, 112, 393-399,https://doi.org/10.1016/j.colsurfb.2013.08.009.

23. Sweety, K.; Deepti, P.; Neelam, P.; Viney, L. Nanostructured Lipid Carriers for Topical Delivery of An AntiAcne Drug: Characterization and ex vivo Evaluation. Pharmaceutical Nanotechnology 2015, 3, 122133,https://doi.org/10.2174/221173850302151116124757.

24. Rajinikanth, P.S.; Chellian, J. Development and evaluation of nanostructured lipid carrier-based hydrogel for topical delivery of 5-fluorouracil. Int J Nanomed. 2016, 11, 5067-5077, https://doi.org/10.2147/IJN.S117511.

25. Sütő, B.; Berkó, S.; Kozma, G.; Kukovecz, Á.; Budai-Szücs, M.; Erős, G.; Kemény, L.; Sztojkov-Ivanov, A.; Gáspár, R.; Csányi, E. Development of ibuprofen-loaded nanostructured lipid carrier-based gels: characterization and investigation of in vitro and in vivo penetration through the skin. International journal of nanomedicine 2016, 11, 1201-1212,https://doi.org/10.2147/IJN.S99198.

26. Nagaich, U.; Gulati, N. Nanostructured lipid carriers (NLC) based controlled release topical gel of clobetasol propionate: design and in vivo characterization. Drug Delivery and Translational Research 2016, 6, 289298,https://doi.org/10.1007/s13346-016-0291-1.

27. Kenechukwu, F.C.; Attama, A.A.; Ibezim, E.C.; Nnamani, P.O.; Umeyor, C.E.; Uronnachi, E.M.; Gugu, T.H.; Momoh, M.A.; Ofokansi, K.C.; Akpa, P.A. Surface-modified mucoadhesive microgels as a controlled release system for miconazole nitrate to improve localized treatment of vulvovaginal candidiasis. European Journal of Pharmaceutical Sciences 2018, 111, 358-375,http://dx.doi.org/10.1016/j.ejps.2017.10.002.

28. Kenechukwu, F.C.; Momoh, M.A.; Nnamani, P.O.; Attama, A.A. Solid lipid micro-dispersions (SLMs) based on PEGylated solidified reverse micellar solutions (SRMS): a novel carrier system for gentamicin. Drug Delivery 2015, 22, 710-722,https://doi.org/10.3109/10717544.2014.900152.

29. Ryan, S.M.; Mantovani, G.; Wang, X.; Haddleton, D.M.; Brayden, D.J. Advances in PEGylation of important biotech molecules: delivery aspects. Expert Opinion on Drug Delivery 2008, 5, 371-383, https://doi.org/10.1517/17425247.5.4.371.

30. Wang, L.; Luo, Q.; Lin, T.; Li, R.; Zhu, T.; Zhou, K.; Ji, Z.; Song, J.; Jia, B.; Zhang, C.; Chen, W.; Zhu, G. PEGylated nanostructured lipid carriers (PEG-NLC) as a novel drug delivery system for biochanin A. Drug Development and Industrial Pharmacy 2015, 41, 1204-1212,https://doi.org/10.3109/03639045.2014.938082. 
31. Babalola CP, Oluwalana I, Kotila OA, Adegoke OA, Kolade YT, Ameh SJ. A novel derivatization ultraviolet spectrophotometric method for the determination of dihydroartemisinin using p-nitroaniline. Trop J Pharm Res. 2014, 13, 127-133, http://dx.doi.org/10.4314/tjpr.v13i1.18.

32. Wang, Y.; Jiang, S.; Wang, H.; Bie, H. A mucoadhesive, thermoreversible in situ nasal gel of geniposide for neurodegenerative diseases. PLOS ONE2017, 12, https://doi.org/10.1371/journal.pone.0189478.

33. Sharma, G.; Dhankar, G.; Thakur, K.; Raza, K.; Katare, O.P. Benzyl Benzoate-Loaded Microemulsion for Topical Applications: Enhanced Dermatokinetic Profile and Better Delivery Promises. AAPS PharmSciTech 2016, 17, 1221-1231,https://doi.org/10.1208/s12249-015-0464-0.

34. Nnamani, P.O.; Kenechukwu, F.C.; Dibua, E.U.; Ogbonna, C.C.; Monemeh, U.L.; Attama, A.A. Transdermal microgels of gentamicin. European Journal of Pharmaceutics and Biopharmaceutics 2013, 84, 345354,http://dx.doi.org/10.1016/j.ejpb.2012.11.015.

35. Shen, C.-Y.; Xu, P.-H.; Shen, B.-D.; Min, H.-Y.; Li, X.-R.; Han, J.; Yuan, H.-L. Nanogel for dermal application of the triterpenoids isolated from Ganoderma lucidum (GLT) for frostbite treatment. Drug Delivery 2016, 23, 610-618,https://doi.org/10.3109/10717544.2014.929756.

36. Khurana, S.; Bedi, P.M.S.; Jain, N.K. Preparation and evaluation of solid lipid nanoparticles based nanogel for dermal delivery of meloxicam. Chemistry and Physics of Lipids 2013, 175-176, 65-72, http://dx.doi.org/10.1016/j.chemphyslip.2013.07.010.

37. Pham, C.V.; Van, M.C.; Thi, H.P.; Thanh, C.Đ.; Ngoc, B.T.; Van, B.N.; Le Thien, G.; Van, B.N.; Nguyen, C.N. Development of ibuprofen-loaded solid lipid nanoparticle-based hydrogels for enhanced in vitro dermal permeation and in vivo topical anti-inflammatory activity. Journal of Drug Delivery Science and Technology 2020, 57, https://doi.org/10.1016/j.jddst.2020.101758.

38. International Conference on harmonization of technical requirements for registration of pharmaceuticals for human use. Stability testing of new drug substances and products, Q1A (R2), European Medicines Agency, Geneva, Switzerland, CPMP/ICH/2736/99; 2003.

39. Zhang, X.; Gan, Y.; Gan, L.; Nie, S.; Pan, W. PEGylated nanostructured lipid carriers loaded with 10hydroxycamptothecin: an efficient carrier with enhanced anti-tumour effects against lung cancer. J. Pharm. Pharmacol. 2008, 60, 1077-1087.

40. Pardeike, J.; Weber, S.; Zarfl, H.P.; Pagitz, M.; Zimmer, A. Itraconazole-loaded nanostructured lipid carriers (NLC) for pulmonary treatment of aspergillosis in falcons. European Journal of Pharmaceutics and Biopharmaceutics 2016, 108, 269-276,http://dx.doi.org/10.1016/j.ejpb.2016.07.018.

41. Liu, J.; Hu, W.; Chen, H.; Ni, Q.; Xu, H.; Yang, X. Isotretinoin-loaded solid lipid nanoparticles with skin targeting for topical delivery. International Journal of Pharmaceutics 2007, 328, 191195,https://doi.org/10.1016/j.ijpharm.2006.08.007.

42. Ali, Z.; Mishra, N.; Baldi, A. Development and characterization of arteether-loaded nanostructured lipid carriers for the treatment of malaria. Artificial Cells, Nanomedicine, and Biotechnology 2016, 44, 545549,https://doi.org/10.3109/21691401.2014.968821.

43. Chukwuebuka, E.U.; Onyedikachi, O.; Rozeeta, C.; Anthony, A. Development Insights of Surface Modified Lipid Nanoemulsions of Dihydroartemisinin for Malaria Chemotherapy: Characterization, and in vivo Antimalarial Evaluation. Recent Patents on Biotechnology 2019, 13, 149165,https://doi.org/10.2174/1872208313666181204095314.

44. Sánchez-López, E.; Ettcheto, M.; Egea, M.A.; Espina, M.; Cano, A.; Calpena, A.C.; Camins, A.; Carmona, N.; Silva, A.M.; Souto, E.B.; García, M.L. Memantine loaded PLGA PEGylated nanoparticles for Alzheimer's disease: in vitro and in vivo characterization. Journal of Nanobiotechnology 2018, 16,https://doi.org/10.1186/s12951-018-0356-z.

45. Awofisayo, S.O.; Igwe, C.N.; Jonathan, N.A.; Francis, A.I.; Ojobor, P.D. In vitro studies of food interaction with dihydroartemisinin-piperaquine antimalarial tablet. J. Pharm. Res. Int. 2017, 18, 1-13, https://doi.org/10.9734/JPRI/2017/28516.

46. Shrotriya, S.; Ranpise, N.; Satpute, P.; Vidhate, B. Skin targeting of curcumin solid lipid nanoparticlesengrossed topical gel for the treatment of pigmentation and irritant contact dermatitis. Artificial Cells, Nanomedicine, and Biotechnology 2018, 46, 1471-1482,http://dx.doi.org/10.1080/21691401.2017.1373659.

47. Narang, A.S.; Srivastava, A.K. Evaluation of Solid Dispersions of Clofazimine. Drug Development and Industrial Pharmacy 2002, 28, 1001-1013,https://doi.org/10.1081/DDC-120006431.

48. Ansari, M.T.; Iqbal, I.; Sunderland, V.B. Dihydroartemisinin-cyclodextrin complexation: Solubility and stability. Archives of Pharmacal Research 2009, 32, 155-165, https://doi.org/10.1007/s12272-009-1130-4.

49. Nagarsenker, M.S.; Joshi, M.S. Celecoxib-Cyclodextrin Systems: Characterization and Evaluation of In Vitro and In Vivo Advantage. Drug Development and Industrial Pharmacy 2005, 31, 169178,https://doi.org/10.1081/DDC-200047795.

50. Ansari, M.T.; Sunderland, V.B. Solid dispersions of dihydroartemisinin in polyvinylpyrrolidone. Archives of Pharmacal Research 2008, 31, 390-398, https://doi.org/10.1007/s12272-001-1169-6.

51. Parapini, S.; Olliaro, P.; Navaratnam, V.; Taramelli, D.; Basilico, N. Stability of the antimalarial drug dihydroartemisinin under physiologically relevant conditions: implications for clinical treatment and pharmacokinetic and in vitro assays. Antimicrob. Agents Chemother. 2015, 59, 4046-4052, https://doi.org/10.1128/AAC.00183-15. 
52. Haynes, R.K.; Chan, H.-W.; Lung, C.-M.; Ng, N.-C.; Wong, H.-N.; Shek, L.Y.; Williams, I.D.; Cartwright, A.; Gomes, M.F. Artesunate and Dihydroartemisinin (DHA): Unusual Decomposition Products Formed under Mild Conditions and Comments on the Fitness of DHA as an Antimalarial Drug. ChemMedChem 2007, 2, 1448-1463,https://doi.org/10.1002/cmdc.200700064

53. Doelker, E. Cellulose derivatives. In: Biopolymers I. Advances in Polymer Science.Langer, R.S.; Peppas, N.A. (eds) Springer, Berlin, Heidelberg, Volume 107,1993;pp. 199-265, https://doi.org/10.1007/BFb0027554.

54. An, D.; Zhao, D.; Li, X.; Lu, X.; Qiu, G.; Shea, K.J. Synthesis of surfactant-free hydroxypropylcellulose nanogel and its dual-responsive properties. Carbohydrate Polymers 2015, 134, 385-389, https://doi.org/10.1016/j.carbpol.2015.08.009.

55. Ning, M.; Guo, Y.; Pan, H.; Chen, X.; Gu, Z. Preparation, in Vitro and in Vivo Evaluation of Liposomal/Niosomal Gel Delivery Systems for Clotrimazole. Drug Development and Industrial Pharmacy 2005, 31, 375-383,https://doi.org/10.1081/DDC-54315.

56. Johal, H.S.; Garg, T.; Rath, G.; Goyal, A.K. Advanced topical drug delivery system for the management of vaginal candidiasis. Drug Delivery 2016, 23, 550-563,https://doi.org/10.3109/10717544.2014.928760.

57. Pantelic, I.; Lukic, M.; Markovic, B.; Lusiana; Hoffmann, C.; Müller-Goymann, C.; Milic, J.; Daniels, R.; Savic, S. Development of a prospective isopropyl alcohol-loaded pharmaceutical base using simultaneous in vitro/in vivo characterization methods of skin performance. Drug Development and Industrial Pharmacy 2014, 40, 960-971, https://doi.org/10.3109/03639045.2013.794827.

58. Marques, A.C.; Rocha, A.I.; Leal, P.; Estanqueiro, M.; Lobo, J.M.S. Development and characterization of mucoadhesive buccal gels containing lipid nanoparticles of ibuprofen. International Journal of Pharmaceutics 2017, 533, 455-462,http://dx.doi.org/10.1016/j.ijpharm.2017.04.025.

59. Pantelić, I.; Lukić, M.; Gojgić-Cvijović, G.; Jakovljević, D.; Nikolić, I.; Lunter, D.J.; Daniels, R.; Savić, S. Bacillus licheniformis levan as a functional biopolymer in topical drug dosage forms: From basic colloidal considerations to actual pharmaceutical application. European Journal of Pharmaceutical Sciences 2020, 142,https://doi.org/10.1016/j.ejps.2019.105109.

60. Ahmad, F.; Alam, M.; Khan, Z.; Khar, R.; Ali, M. Development and evaluation of an acid buffering bioadhesive vaginal gel for mixed vaginal infections. Acta Pharmaceutica 2008, 58, 407419,https://doi.org/10.2478/v10007-008-0023-2.

61. Avasatthi, V.; Pawar, H.; Dora, C.P.; Bansod, P.; Gill, M.S.; Suresh, S. A novel nanogel formulation of methotrexate for topical treatment of psoriasis: optimization, in vitro and in vivo evaluation. Pharmaceutical Development and Technology 2016, 21, 554-562,https://doi.org/10.3109/10837450.2015.1026605.

62. Wang, G.; Nie, Q.; Zang, C.; Zhang, B.; Zhu, Q.; Luo, G.; Wang, S. Self-Assembled Thermoresponsive Nanogels Prepared by Reverse Micelle \&\#x2192; Positive Micelle Method for Ophthalmic Delivery of Muscone, a Poorly Water-Soluble Drug. Journal of Pharmaceutical Sciences 2016, 105, 2752-2759, http://dx.doi.org/10.1016/j.xphs.2016.02.014.

63. Massella, D.; Leone, F.; Peila, R.; Barresi, A.A.; Ferri, A. Functionalization of Cotton Fabrics with Polycaprolactone Nanoparticles for Transdermal Release of Melatonin. Journal of Functional Biomaterials 2018, 9,https://doi.org/10.3390/jfb9010001.

64. Baek, J.-S.; Cho, C.-W. Surface modification of solid lipid nanoparticles for oral delivery of curcumin: Improvement of bioavailability through enhanced cellular uptake, and lymphatic uptake. European Journal of Pharmaceutics and Biopharmaceutics 2017, 117, 132-140,http://dx.doi.org/10.1016/j.ejpb.2017.04.013.

65. Lunter, D.J.; Rottke, M.; Daniels, R. Oil-in-Oil-Emulsions with Enhanced Substantivity for the Treatment of Chronic Skin Diseases. Journal of Pharmaceutical Sciences 2014, 103, 15151519,https://doi.org/10.1002/jps.23944.

66. Duarah, S.; Durai, R.D.; Narayanan, V.B. Nanoparticle-in-gel system for delivery of vitamin C for topical application. Drug Delivery and Translational Research 2017, 7, 750-760,https://doi.org/10.1007/s13346017-0398-Z.

67. Elnaggar, Y.S.R.; Talaat, S.M.; El-Din, M.B.; Abdallah, O.Y. Novel lecithin-integrated liquid crystalline nanogels for enhanced cutaneous targeting of terconazole: development, in vitro and in vivo studies. Int. J. Nanomed. 2016, 11, 5531-5547, https://doi.org/10.2147/IJN.S117817.

68. Divya, G.; Panonnummal, R.; Gupta, S.; Jayakumar, R.; Sabitha, M. Acitretin and aloe-emodin loaded chitin nanogel for the treatment of psoriasis. European Journal of Pharmaceutics and Biopharmaceutics 2016, 107, 97-109,http://dx.doi.org/10.1016/j.ejpb.2016.06.019.

69. Khurana, S.; Jain, N.K.; Bedi, P.M.S. Nanostructured lipid carriers based nanogel for meloxicam delivery: mechanistic, in-vivo and stability evaluation. Drug Development and Industrial Pharmacy 2015, 41, 13681375,https://doi.org/10.3109/03639045.2014.950586.

70. Jansen, F.H. The pharmaceutical death-ride of dihydroartemisinin. Malaria J. 2010, 9,https://doi.org/10.1186/1475-2875-9-212, 